\title{
Regulation of Rubisco activity and its potential effect on photosynthesis during mixing in a turbid estuary
}

\author{
H. L. MacIntyre*, R. J. Geider** \\ College of Marine Studies, University of Delaware, 700 Pilottown Road, Lewes, Delaware 19958, USA
}

\begin{abstract}
The recent demonstration that Rubisco activity in phytoplankton is regulated in response to changes in irradiance allows development of a mechanistic model of the photosynthetic response to fluctuating irradiance. The model was used to predict photosynthetic responses during mixing in estuarine systems, the only environments in which the rate of change of irradiance is likely to occur on time scales comparable to induction of photosynthesis. Non-steady-state rates of photosynthesis were calculated based on the lags associated with activation and deactivation of Rubisco in response to an increase or decrease in irradiance. Non-steady-state rates were compared with steady-state rates, calculated assuming an instantaneous change in photosynthetic response to a change in irradiance. Simulations were run for a deep, relatively clear estuary and a shallow, turbid estuary, using input parameters measured in Delaware Bay (DE, USA) and San Antonio Bay (TX, USA), respectively. When estimates of production are based on steady-state rates of photosynthesis, the model predicts average overestimates of $14 \%$ in the former and $22 \%$ in the latter Sensitivity analyses show that, within the range of reported values, the model is more sensitive to changes in turbidity than to changes in the depth of the mixed layer, incident irradiance or diffusivity. When compared with published data, the model tended to overestimate the reduction in photosynthesis in the deep bay condition, possibly because of a compensating increase in photosynthesis due to alleviation of feedback limitation by mixing. In contrast, the model provided reasonably accurate estimates in the shallow bay condition. This suggests that while induction is unlikely to impose a constraint on production in relatively deep and clear estuaries such as Delaware Bay, it may impose a severe constraint in the shallow, turbid estuaries typified by San Antonio Bay
\end{abstract}

KEY WORDS: Estuary - Feedback limitation - Induction Kinetic - Mixing · Model P Photosynthesis Photosynthetic regulation - Rubisco

\section{INTRODUCTION}

One of the characteristics that distinguish estuaries from the coastal and open ocean is the rate at which their flora are mixed through the photic zone. On the continental shelf, where the photic zone might be $50 \mathrm{~m}$ deep and the coefficient of vertical diffusivity about $5 x$ $10^{-3} \mathrm{~m}^{2} \mathrm{~s}^{-1}\left(50 \mathrm{~cm}^{2} \mathrm{~s}^{-1}\right)$, a phytoplankter entrained in the mixed layer would traverse the photic zone, and so

\footnotetext{
•E-mail: hmac@udel.edu

- Present address: Marine Biological Association of the UK,

The Laboratory, Citadel Hill, Plymouth PL1 2PB, United Kingdom
}

the full gradient of irradiance in the mixed layer, in about $3 \mathrm{~d}$. In an estuary with a photic zone $2 \mathrm{~m}$ deep, an entrained phytoplankter would traverse the same range of irradiances in 13 min, given the same mean diffusivity. Even more rapid transients in irradiance are likely to be common in shallow, turbid estuaries such as the lagoonal bays that lie behind barrier islands on the Atlantic and Gulf coasts of the United States. In these shallow waters, the photic zone may be less than $0.5 \mathrm{~m}$ deep because of resuspension of sediment by wind-driven mixing (Gabrielson \& Lukatelich 1985, Pejrup 1986, Arfi et al. 1993), tides (Litaker et al. 1987, Cloern et al. 1989), or anthropogenic activity (Anderson 1976, Garrad \& Hey 1987) and phytoplank- 
ton may be mixed through most of the photic zone in 3 to 4 min (Macintyre 1993). Shallow and turbid bays can be moderately to highly productive (Randall \& Day 1987, Boyer et al. 1993, MacIntyre \& Cullen 1996), although a gradient of decreasing production with increasing turbidity has been demonstrated in the Dutch Waddensee (The Netherlands; Cadée \& Hegeman 1974), San Francisco Bay (USA; Cole \& Cloern 1984), Bristol Channel (UKi Joint \& Pomeroy 1981), Delaware Bay (DE, USA; Pennock \& Sharp 1986), Fourleague Bay (LA, USA; Randall \& Day 1987) and the Neuse River Estuary (NC, USA; Boyer et al. 1993).

The photosynthesis-irradiance relationship, which is the basis for many estimates of productivity by phytoplankton, is very noisy under conditions where the light field fluctuates (Marra \& Heinemann 1982, Kirkpatrick et al. 1990). Several studies have examined the effect that fluctuations in the light field have on productivity, imposing changes that range from the highfrequency fluctuations caused by wave-focusing (Fréchette \& Legendre 1978) to simulations representative of Langmuir circulation (Marra 1978a, b, Yoder \& Bishop 1985, Randall \& Day 1987, Mallin \& Paerl 1992) or turbulent mixing (Gallegos \& Platt 1982). One cannot generalize the effect of mixing because the mixing regime has variously been shown to enhance (Marra 1978a, b, Mallin \& Paerl 1992), reduce (Randall \& Day 1987) and have no effect on (Gallegos \& Platt 1982 , Yoder \& Bishop 1985) productivity relative to a static control.

Data collected by Marra (1978a, b), Marra \& Heinemann (1982) and Cullen \& Lewis (1988) have been the basis of several models that relate photosynthesis to changes in irradiance (Neale \& Marra 1985, Denman \& Marra 1986, Pahl-Wostle \& Imboden 1990, Franks \& Marra 1994, Barkmann \& Woods 1996). These have in common that they have focused on the time dependence of light-saturated rate of photosynthesis but, with the exception of the DYPHORA model (Pahl-Wostle \& Imboden 1990), the time constants that are incorporated are characteristic of photoacclimation, photoinhibition or both. These processes are associated with the breakdown and synthesis of cellular components, processes that occur over a period of hours (Cullen \& Lewis 1988, Kromkamp \& Limbeek 1993). Consequently, the time constants embedded in the empirical models match the time scales of mixing in nearshore systems, where the rate of change of irradiance is comparatively slow, but may not describe the responses in estuarine environments, where the rate of change can be very rapid.

The mechanisms that underlie photosynthetic responses to variable light fields have also been examined in vascular plants. The focus of this research has been on the frequencies of response to sun-flecks, the changes in irradiance that arise in the understory when there are movements in the plant canopy overhead, and to the appearance of holes in the canopy (Pearcy 1990, 1995). The time scales of these are likely to be much faster and much slower, respectively, than changes associated with mixing in an estuarine system and the amplitudes much lower. However, research on vascular plants has also elucidated some of the changes that occur during photosynthetic induction. One of the limiting steps is likely to be the light-sensitive activation and deactivation of ribulose-1,5-bisphosphate oxygenase/carboxylase (Rubisco), the enzyme that catalyses carboxylation in the Calvin cycle (Woodrow \& Mott 1989, Lan et al. 1992, Sassenrath-Cole et al. 1994). In contrast to photoacclimation, this level of regulation depends on the activity of the pool of enzyme rather than the size of the pool and proceeds at rates that may match the rate of change in irradiance for a cell mixed through the water column in an estuary.

The demonstration that Rubisco activity is regulated in response to changes in irradiance (Macintyre et al. 1996) and measurement of the time constants associated with activation and deactivation of the enzyme (MacIntyre 1996) allow us to develop a mechanistic model for examining the effects of rapid fluctuations in irradiance characteristic of an estuarine environment. The model is based on the regulation of Rubisco in both cultures of marine diatoms and a natural assemblage dominated by Skeletonema costatum and is tested under conditions that are characteristic of a relatively deep, clear estuary and a shallow, turbid estuary. Comparisons of the model's predictions with published data suggest that induction may place a severe constraint on photosynthesis in turbid waters.

\section{THE BASIS OF THE MODEL}

A number of mechanisms associated with the processes of photosynthesis, photoinhibition, photoprotection and photoacclimation operate to modulate the photosynthesis-irradiance response on time scales of seconds to days. This model is restricted to a consideration of the light-sensitive activation and deactivation of Rubisco. The model is based on the following assumptions: (1) Rubisco activity is regulated in response to changes in irradiance; (2) the light-saturated rate of photosynthesis is determined by the maximum activity of Rubisco; (3) the rate at which photosynthesis is induced (i.e. the rapidity with which the photosynthetic rate rises after an increase in irradiance) is limited by the kinetics of Rubisco's activation; and (4) the reduction in the rate of photosynthesis that occurs when irradiance falls can be described by the kinetics of Rubisco's deactivation. 
Data to test these assumptions were collected on cultures of marine diatoms and a diatom-dominated assemblage from Delaware Bay.

\section{MATERIAL AND METHODS}

Culture conditions. Cultures of the diatoms Phaeodactylum tricornutum. Thalassiosira weissflogii and $T$. pseudonana were grown in off hore seawater enriched to $\mathrm{f} / 2$ nutrient concentrations with $100 \mu \mathrm{M}$ silicate (Guillard 1975). The cultures were grown on a $12: 12 \mathrm{~h}$ light:dark cycle ( $T$. weissflogii) or under continuous light (P. tricornutum and T.pseudonana) of $180 \mu \mathrm{mol}$ photons $\mathrm{m}^{-2} \mathrm{~s}^{-1}$ at $20 \pm 0.5^{\circ} \mathrm{C}$. The cultures were stirred and bubbled with air that was passed through an activated charcoal filter and a $0.2 \mu \mathrm{m}$ pore Acrodisc filter before entering the culture vessels. Samples were monitored daily for chlorophyll content, cell number and fluorescence in vivo $\left(F_{v} / F_{m}\right.$ as determined from dark-adapted fluorescence in the presence and absence of $30 \mu \mathrm{M}$ DCMU 3-(3,4-dichlorophenyl)-1,1-dimethylurea) and were maintained in exponential phase growth.

Determination of photosynthetic rates. Photosynthesis-irradiance ( $P I_{i}$ see Table 1 for abbreviations) curves were determined from the variation in shortterm photosynthetic rates over a range of irradiances at the growth temperature (Lewis \& Smith 1983). Samples were inoculated with $5 \mu \mathrm{Ci} \mathrm{ml} \mathrm{m}^{-1}$ of $\mathrm{NaH}^{14} \mathrm{CO}_{3}$ (58 $\mathrm{Ci} \mathrm{mol}{ }^{-1}$, Amersham CFA.3) and incubated for
$20 \mathrm{~min}$. The incubation was terminated by adding $50 \mu \mathrm{l}$ of formalin to each aliquot and residual inorganic carbon was driven off by addition of $250 \mu \mathrm{l}$ of $6 \mathrm{~N} \mathrm{HCl}$ and shaking for 60 to $90 \mathrm{~min}$. Incorporation of ${ }^{14} \mathrm{C}$ label was determined by liquid scintillation counting. The PI curve was determined by non-linear least-squares fitting to the following model (Webb et al. 1974):

$$
P^{\mathrm{chl}}=P_{\mathrm{m}}^{\mathrm{chi}}\left[1-\exp \left(\frac{-\alpha^{\mathrm{chl} I}}{P_{\mathrm{m}}^{\mathrm{chl}}}\right)\right]+P_{0}^{\mathrm{chl}}
$$

where $P^{\mathrm{chl}}\left[\mathrm{g} \mathrm{C}(\mathrm{g} \mathrm{chl})^{-1} \mathrm{~h}^{-1}\right]$ is the chlorophyll-specific rate of photosynthesis at irradiance $I$ ( $\mu \mathrm{mol}$ photons $\left.\mathrm{m}^{-2} \mathrm{~s}^{-1}\right) ; P_{\mathrm{m}}^{\mathrm{chl}}\left[\mathrm{gC}(\mathrm{g} \mathrm{chl})^{-1} \mathrm{~h}^{-1}\right]$ is the light-saturated rate of photosynthesis; $\alpha^{\mathrm{ch}]}$ [g $\mathrm{C}(\mathrm{g} \mathrm{chl})^{-1}$ ( $\mu$ mol photons $\left.\left.\mathrm{m}^{-2}\right)^{-1}\right]$ is the initial slope of the $P I$ curve and $P_{0}^{\mathrm{chl}}[\mathrm{g} \mathrm{C}$ $(\mathrm{g} \mathrm{chl})^{-1} \mathrm{~h}^{-1}$ ] is an intercept parameter included to improve the distribution of residuals at low irradiances.

The variation in photosynthetic rates over time during induction was determined as described by MacIntyre et al. (1996). Briefly, a $40 \mathrm{ml}$ aliquot of sample was dark-adapted for 60 to $90 \mathrm{~min}$ and then enriched with $5 \mu \mathrm{Ci} \mathrm{m} l^{-1} \mathrm{NaH}^{14} \mathrm{CO}_{3}$ and allowed to equilibrate for $5 \mathrm{~min}$. The sample was then returned to saturating irradiance and successive $1 \mathrm{ml}$ aliquots removed and killed with $150 \mu \mathrm{l}$ of formalin. Aliquots were removed every $15 \mathrm{~s}$ for $5 \mathrm{~min}$ and then every $60 \mathrm{~s}$ for a further $15 \mathrm{~min}$. Incorporation was determined as described above. The change in rate of carbon fixation was assumed to follow a first-order rate reaction. The time constant for photosynthetic induction was determined

Table 1. Symbols, terms and abbreviations used in the text

\begin{tabular}{|c|c|c|}
\hline Symbol & Definition & Units \\
\hline$A_{\mathrm{d}}^{\text {chl }}$ & Minimum (i.e. dark-adapted) rate of Rubisco activity in vitro & $g C(g c h l)^{-1} h^{-1}$ \\
\hline$A_{\mathrm{r}}^{\mathrm{chl}}$ & Maximum rate of Rubisco activity in vitro & $g \subset(g \mathrm{chl})^{-1} \mathrm{~h}^{-1}$ \\
\hline$A^{*}$ & Instantaneous rate of Rubisco activity & Dimensionless \\
\hline$a^{\text {chl }}$ & Initial slope of the PI curve & $g \subset(g \mathrm{chl})^{-1}\left(\mu \mathrm{mol} \text { photons } \mathrm{m}^{-2}\right)^{-1}$ \\
\hline$I_{k}$ & Saturation parameter of the $P I$ curve, $=P_{\mathrm{m}}^{\mathrm{chl}} / \alpha^{\mathrm{chl}}$ & $\mu \mathrm{mol} \mathrm{m}{ }^{-2} \mathrm{~s}^{-1}$ \\
\hline$I_{0}$ & Incident irradiance & $\mu \mathrm{mol} \mathrm{m} \mathrm{m}^{-2} \mathrm{~s}^{-1}$ \\
\hline$I_{z}$ & Irradiance at depth $z$ & $\mu \mathrm{mol} \mathrm{m} \mathrm{m}^{-2} \mathrm{~s}^{-1}$ \\
\hline$k$ & Diffuse attenuation coefficient & $\mathrm{m}^{-1}$ \\
\hline$K_{z}$ & Coefficient of vertical diffusivity & $\mathrm{m}^{-2} \mathrm{~s}^{-1}$ \\
\hline PI & Photosynthesis vs irradiance & \\
\hline$P_{\mathrm{m}}^{\mathrm{chl}}$ & Maximum rate of photosynthesis at steady state & $g C(g \operatorname{chl})^{-1} h^{-1}$ \\
\hline$V_{m}^{\text {chl }}$ & Maximum rate of photosynthesis in the absence of feedback limitation & $g C(g c h l)^{-1} h^{-1}$ \\
\hline${ }^{s} P^{*}$ & Rate of photosynthesis, assuming steady-state (instantaneous) response & Dimensionless \\
\hline${ }^{n} P^{*}$ & Rate of photosynthesis, assuming non-steady-state (delayed) response & Dimensionless \\
\hline$R^{n / s}$ & Achieved photosynthesis, ratio of ${ }^{n} P^{*}$ to ${ }^{s} P^{*}$ integrated over time & Dimensionless \\
\hline$\tau_{\mathrm{d}}$ & Time constant of activation of Rubisco during a dark-light transition & $\min$ \\
\hline$\tau_{\mathrm{d}}$ & Time constant of deactivation of Rubisco during a light-dark transition & $\min$ \\
\hline$\tau_{p}$ & Time constant of photosynthetic induction during a dark-light transition & $\min$ \\
\hline$z$ & Depth & $\mathrm{m}$ \\
\hline$z_{\text {eu }}$ & Depth of the photic zone,$=\ln (0.01) / \mathrm{K}$ & $\mathrm{m}$ \\
\hline$z_{\mathrm{m}}$ & Depth of the mixed layer & $\mathrm{m}$ \\
\hline
\end{tabular}


by non-linear least-squares fit to the following equation (see Appendix 1 for derivation):

$$
C^{\text {chl }}=V_{\mathrm{ml}}^{\text {chil }} t-\tau_{\mathrm{p}}\left(V_{\mathrm{m}}^{\mathrm{chl}}-P_{\mathrm{i}}^{\mathrm{chl} l}\right)\left[1-\exp \left(\frac{-t}{\tau_{p}}\right)\right]
$$

where $C^{\text {chl }}\left[\mathrm{gC}(\mathrm{g} \mathrm{chl})^{-1}\right]$ is the chlorophyll-specific amount of carbon fixed at time $t$ (min) after the shift into saturating irradiance; $P_{\mathrm{c}}^{\mathrm{chl}}$ and $V_{\mathrm{m}}^{\mathrm{chl}}\left[\mathrm{g} \mathrm{C}(\mathrm{g} \mathrm{chl})^{-1}\right.$ $\mathrm{h}^{-1}$ ] are the initial and light-saturated rates of photosynthesis; and $\tau_{\mathrm{p}}$ (min) is the time constant that characterizes the increase in the rate of photosynthesis over time. Note that the light-saturated rate of photosynthesis, $V_{\mathrm{m}}^{\mathrm{chl}}$, is distinguished from that obtained in Eq. (1), $P_{\mathrm{m}}^{\mathrm{chl}}$, because of a bias that may arise from the 2 distinct operational definitions. The 2 measurements may differ considerably (MacIntyre et al. 1996).

Determination of Rubisco activity. Rubisco activity was determined in vitro in crude cell extracts. Small (10 to $30 \mathrm{ml}$ ) aliquots were collected onto GF/F filters under low irradiance, flash-frozen and stored in liquid nitrogen until assay. Rubisco activity was assayed in crude extracts after extraction by vigorous grinding in a tissue homogenizer for $40 \mathrm{~s}$ in $2 \mathrm{ml}$ of extraction buffer. After grinding, the slurry was centrifuged at $13900 \times g$ for $10 \mathrm{~s}$ to remove debris, and $150 \mu \mathrm{l}$ of the supernatant assayed for Rubisco activity in $500 \mu$ lof assay buffer. The extraction buffer was $50 \mathrm{mM}$ Bicine, pH 8.0, with $20 \mathrm{mM} \mathrm{MgCl}_{2}, 100 \mu \mathrm{M} \mathrm{NaHCO}, 1 \mathrm{mM}$ EDTA (ethylenediaminetetraacetic acid), $10 \mathrm{mM}$ DTT (dithiothreitol), $0.2 \%$ Triton-X-100 and $15 \mathrm{mg} \mathrm{ml}^{-1}$ PVPP (polyvinylpolypyrrolidone). The assay buffer was $50 \mathrm{mM}$ Bicine, pH 8.2, with $20 \mathrm{mM} \mathrm{MgCl}, 20 \mathrm{mM}$ $\mathrm{NaHCO}_{3}, 1 \mathrm{mM}$ EDTA, $10 \mathrm{mM}$ DTT, $3.5 \mathrm{mM}$ RuBP (ribulose-1, 5-biphosphate) and $20 \mu \mathrm{Ci} \mathrm{ml}{ }^{-1} \mathrm{NaH}^{14} \mathrm{CO}_{3}$. The reaction was stopped after $60 \mathrm{~s}$ by adding $500 \mu \mathrm{l}$ of $6 \mathrm{~N} \mathrm{HCl}$. The samples were shaken for 60 to $90 \mathrm{~min}$ to remove residual inorganic carbon and incorporation was determined by liquid scintillation counting. Uptake rates were expressed relative to the chlorophyll concentration in the crude extract.

Time constants for deactivation of Rubisco were determined by dividing a sample into ten $40 \mathrm{ml}$ aliquots that were pre-incubated at saturating irradiance for $30 \mathrm{~min}$ and then put into darkness. Successive aliquots were filtered and frozen in liquid nitrogen every $5 \mathrm{~min}$ for $60 \mathrm{~min}$. Sample processing took ca $40 \mathrm{~s}$ and was done under low irradiance $\left(<5 \mu \mathrm{mol} \mathrm{m} \mathrm{m}^{-2} \mathrm{~s}^{-1}\right)$. The decline in Rubisco activity was fit by non-linear least-squares regression to a first-order rate equation.

$$
A^{c h l}=\left(A_{\mathrm{m}}^{\mathrm{chl}}-A_{\mathrm{d}}^{\mathrm{chl}}\right) \exp \left(\frac{-t}{\tau_{\mathrm{d}}}\right)+A_{\mathrm{d}}^{\mathrm{chl}}
$$

where $A^{\text {chl }}\left[\mathrm{g} \mathrm{C}(\mathrm{g} \mathrm{chl})^{-1} \mathrm{~h}^{-1}\right]$ is Rubisco activity at time $t$ (min) after the shift into darkness; $A_{\mathrm{m}}^{\mathrm{chl}}$ and $A_{\mathrm{d}}^{\text {chl }}[\mathrm{g} \mathrm{C}$ (g chl. $\left.)^{-1} \mathrm{~h}^{-1}\right]$ are the light-saturated and minimum activities, respectively; and $\tau_{d}(\mathrm{~min})$ is the time constant that characterizes the decrease in activity over time.

The time constant for activation of Rubisco was determined by dividing a sample and treating it as for determination of deactivation (pre-incubation at saturating irradiance for $30 \mathrm{~min}$ followed by incubation in darkness for $60 \mathrm{~min}$ ) and then returning it to saturating irradiance. Successive aliquots were filtered and frozen every $60 \mathrm{~s}$ for $10 \mathrm{~min}$ and every $120 \mathrm{~s}$ for $10 \mathrm{~min}$ thereafter. The increase in Rubisco activity was fit by non-linear least-squares regression to a first-order rate equation:

$$
A^{\mathrm{chl}}=\left(A_{\mathrm{m}}^{\mathrm{chl}}-A_{\mathrm{d}}^{\mathrm{chl}}\right)\left[1-\exp \left(\frac{-t}{\tau_{\mathrm{a}}}\right)\right]+A_{\mathrm{d}}^{\mathrm{chl}}
$$

The parameters are as defined for Eq. (3), except that $t$ (min) is the time after the shift into saturating irradiance and $\tau_{\mathrm{a}}(\mathrm{min})$ is the time constant that characterizes the increase in activity over time.

\section{RESULTS}

Rubisco activity in the diatom Thalassiosira weissflogii is regulated in concert with photosynthetic rate over a range of irradiances (Fig. 1). There was a linear
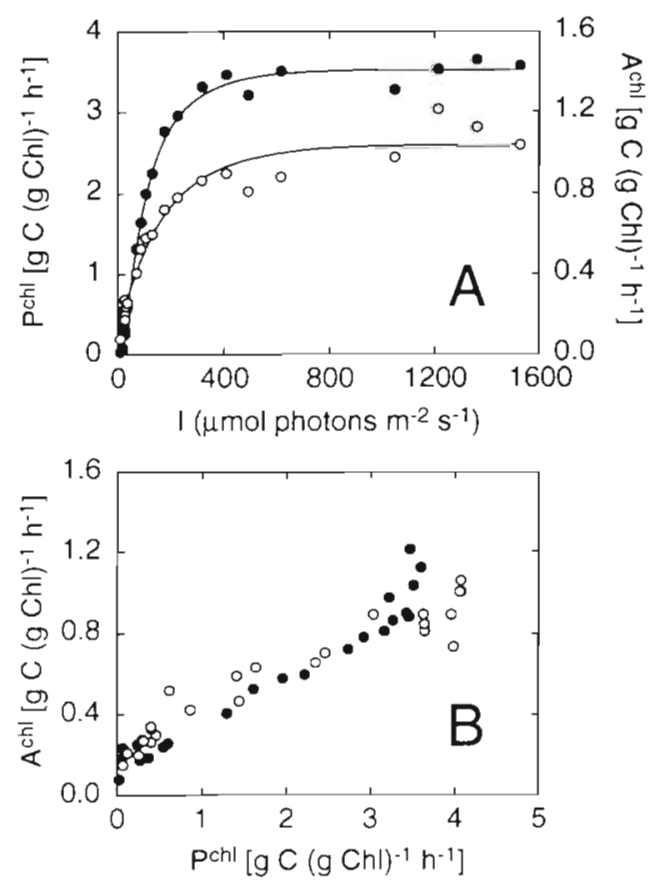

Fig. 1 (A) Variation in photosynthesis, $P^{\text {chl }}$ (•), and Rubisco activity in vitro, $A^{\text {chl }}(0)$, with irradiance in Thalassiosira werssflogii. (B) Relationship between $A^{\text {chl }}$ and $P^{\text {rhl }}$ in $T$, weissflogii in duplıcate cultures [• data in (A)] 


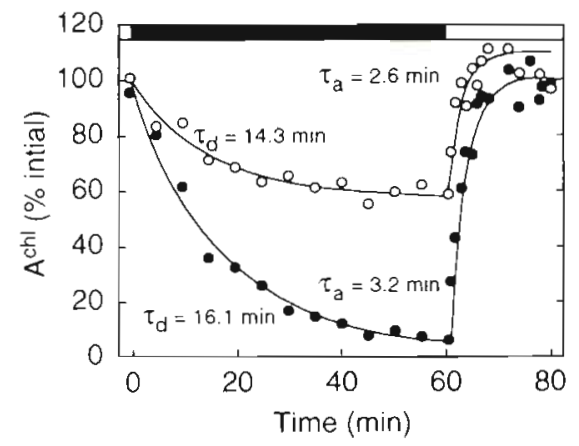

Fig. 2. Time course of deactivation and activation of Rubisco after reciprocal switches between saturating irradiance and darkness. The dark period is indicated by the dark bar. Data are for Thalassiosira weissflogii $(\bullet)$ and a natural assemblage dominated by Skeletonema costatum (o) and have been normalized to the initial value of $A_{m}^{c h l}$ Time constants, $\tau_{d}$ and $\tau_{d}$, were determined by fitting to Eqs. (25) and (26)

relationship between Rubisco activity and photosynthesis, although Rubisco was not fully deactivated in darkness. The time constants of Rubisco's activation and deactivation in a culture of $T$. weissflogii were similar to those of a natural population of net phytoplankton dominated by the diatom Skeletonema costatum, although the ranges of activity differed (Fig. 2). The time constants for deactivation were longer (16.1 and $14.3 \mathrm{~min})$ than the time constants for activation (3.2 and $2.6 \mathrm{~min}$ ) and were similar to those determined on nutrient-replete cultures of the diatoms Phaeodactylum tricornutum and $T$. pseudonana (Table 2).

The time constants for photosynthetic induction were shorter than those for activation of Rubisco but were in some cases sensitive to the duration of the period over which data were fit to Eq. (2) (Fig. 3). Where it occurred, this sensitivity to the duration of the fit was caused by a fall-off in photosynthetic rate after 15 to $20 \mathrm{~min}$ and increased weighting by a preponderance of data at the maximum rate of photosynthesis.
Because first-order rate reactions approach saturation (i.e. $99 \%$ of the final rate) only for $t \geq 4.61 \tau$, data for which $\tau_{\mathrm{p}} \leq t / 4.61$ cannot be considered reliable. For this reason, estimates of $\tau_{\mathrm{p}}$ based on the first 10 min or less of the time course shown in Fig. 3 are assumed to be inaccurate. The data are reported because there is a systematic bias in $\tau_{p}$ with the duration of the fit and estimates based on fits of $11 \mathrm{~min}$ or longer may be compromised by the decline in the light-saturated photosynthetic rate over time.

Estimates of $\tau_{p}$ (measured over the initial $15 \mathrm{~min}$ of a time course) showed little variation with time when samples were dark-adapted for 25 to $70 \mathrm{~min}$ (Fig. 4B) but were frequently lower than $\tau_{a}$ (Fig. 3, Table 2). Because the light-saturated and initial rates of photosynthesis $\left(V_{\mathrm{m}}^{\text {ch }}\right.$ and $P_{\mathrm{i}}^{\mathrm{chl}}$ ) were also sensitive to the duration of the time course when derived by Eq. (2), both were estimated by linear regression of the first and last 5 points in the time course, respectively. The light-saturated rate was higher than under steady-state conditions (Fig. 4C). The decline in the initial rate of photosynthesis on reillumination was comparable to the decline predicted from deactivation of Rubisco (Fig. 4C).

\section{DEVELOPMENT OF THE MODEL}

Research in vascular plants has shown that Rubisco's activity is regulated in response to changes in irradiance and that there is a linear relationship between the activation state and photosynthesis, irrespective of the physiological mechanism by which Rubisco activity is regulated (Seemann et al. 1990). The activation state is also regulated in response to irradiance in phytoplankton, as shown above for Thalassiosira weissflogii (Figs. 1 \& 2) and elsewhere (Mouget et al. 1993, MacIntyre 1996, Macintyre et al. 1996). The first assumption of the model, that Rubisco activity is regulated in response to irradiance, is therefore valid.

Table 2. Time constants for deactivation $\left(\tau_{\dot{\alpha}}\right)$ and activation $\left(\tau_{a}\right)$ of Rubisco and of photosynthetic induction $\left(\tau_{p}\right)$. Estimates were made by fitting data to Eqs. (2), (3) and (4) by non-linear least-squares regression and are presented as mean (SE) $\mathrm{R}^{2}$ The means and standard errors of pooled estimates of $\tau_{d}$ and $\tau_{d}$, chosen as representative for the model simulations, are given below. The natural assemblage, previously described by MacIntyre et al. (1996), was dominated by Skeletonema costatum

\begin{tabular}{|c|c|c|c|c|c|c|c|}
\hline \multirow{2}{*}{$\begin{array}{l}\text { Species } \\
\text { Phaeodactylum tricornutum }\end{array}$} & \multicolumn{3}{|c|}{$\tau_{\mathrm{d}}(\min )$} & \multicolumn{3}{|c|}{$\tau_{\mathrm{a}}(\mathrm{min})$} & \multirow[t]{2}{*}{$\tau_{p}(\min )$} \\
\hline & 18.0 & $(3.1)$ & 0.96 & 5.7 & $(1.6)$ & 0.90 & \\
\hline Thalassiosira weissflogii & 16.1 & $(1.6)$ & 0.99 & 3.2 & $(0.4)$ & 0.97 & $1.8(0.1)$ \\
\hline \multirow[t]{2}{*}{ Thalassiosira pseudonana } & 12.2 & $(1.0)$ & 0.99 & 2.6 & $(0.4)$ & 0.93 & $1.8 \quad(0.5)$ \\
\hline & 17.6 & (2.3) & 0.98 & 3.6 & $(0.8)$ & 0.90 & $2.3 \quad(0.3)$ \\
\hline \multirow[t]{2}{*}{ Natural assemblage } & 20.5 & $(8.5)$ & 0.85 & 4.5 & (1.1) & 0.89 & $3.8(1.6)$ \\
\hline & 14.3 & $(2.6)$ & 0.95 & 2.6 & $(1.0)$ & 0.74 & $1.0 \quad(0.3)$ \\
\hline Pooled estimates & 16.5 & $(2.9)$ & & 3.7 & $(1.2)$ & & \\
\hline
\end{tabular}




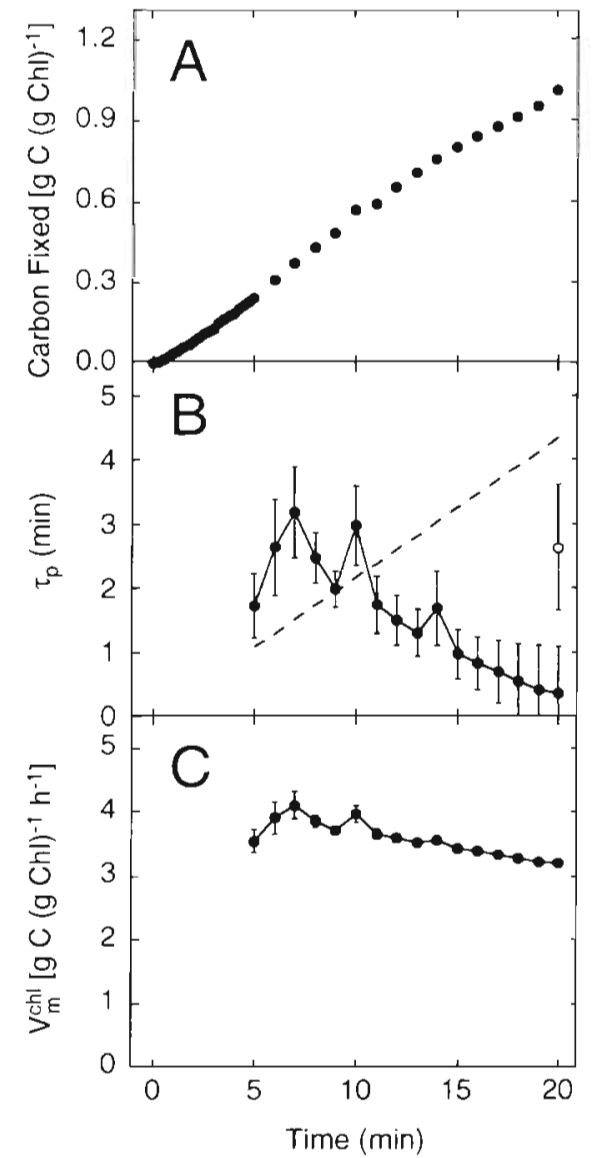

Fig. 3. (A) Time course of carbon uptake over $20 \mathrm{~min}$ in a natural assemblage dominated by Skeletonema costatum. Phytoplankton were exposed to saturating irradiance after $60 \mathrm{~min}$ in darkness. (B) Estimates of the time constant of photosynthetic induction, $\tau_{\mathrm{p}}(\bullet)$, derived by fitting the data in (A) to Eq. (2). Data are plotted against the period over which they were derived. The dashed line is the boundary condition of $t / 4.61$ at which a first-order rate reaction reaches $99 \%$ saturation. Estimates above the line may be unreliable because the light-saturated rate of photosynthesis, $V_{\mathrm{m}}^{\text {chl }}$ will be poorly constrained. However, feedback limitation, as evidenced by the change in the slope at about 10 to $12 \mathrm{~min}$ (A), may lead to an underestimate of $\tau_{p}$ when the time constant is estimated from longer time series. The estimate of $\tau_{\mathrm{c}}(0)$ is shown for comparison. (C) Estimates of the light-saturated rate of photosynthesis after photosynthetic induction, $V_{\mathrm{m}}^{\text {chl }}$, derived by fitting the data in (A) to Eq. (2). Data are plotted against the period over which they were derived

The light-saturated rate of photosynthesis is assumed to be limited by maximum Rubisco activity in vascular plants (Björkman 1981) and a correlation between the two has been demonstrated in phytoplankton (Rivkin 1990, Mouget et al. 1993, MacIntyre et al. 1996). Rubisco activity in vitro is lower than the rate of photosynthesis in most chromophytes (Bush \& Sweeney 1972, Mukerji \& Morris 1976, Glover \& Morris 1979, Whitney \& Yellowlees 1995, MacIntyre et al.
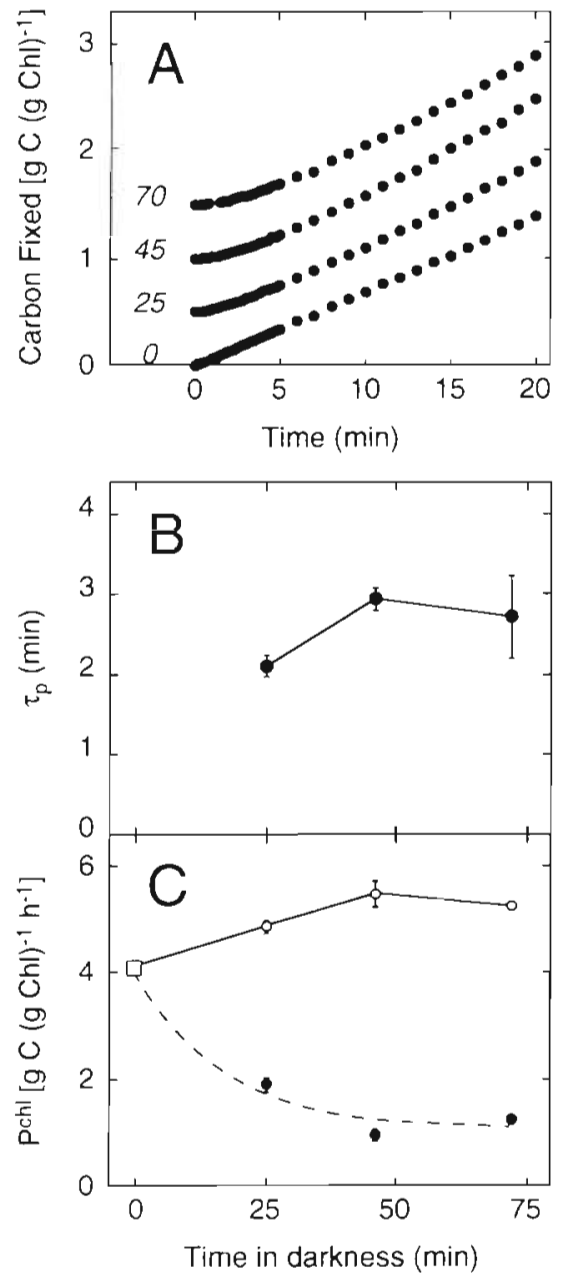

Fig. 4. (A) Time course of carbon uptake over $20 \mathrm{~min}$ in Thalassiosira weissflogii. Cultures were exposed to saturating irradiance at steady state and after 25,45 and 70 min in darkness. Curves have been offset for ease of comparison. (B) Variation in estimates $( \pm \mathrm{SE}$ ) of the time constant of photo-

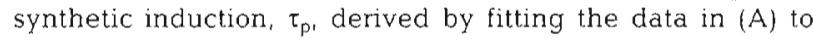
Eq. (2). Estimates are from fits over the first $15 \mathrm{~min}$ of induction. (C) Estimates of the light-saturated rate of photosynthesis after photosynthetic induction, $V_{m}^{\text {chl }}(0)$, and the initial rate of photosynthesis, $P_{1}^{\text {chl }}(\bullet)$. The steady-state rate ( $\square$ ) is shown for comparison. The dashed line is a non-linear regression of $P_{i}^{\text {chl }}$ on the duration of dark adaptation, with the time constant held at $16.5 \mathrm{~min}$

1996) but we assume that this is due to the instability of the enzyme in vitro (Whitney \& Yellowlees 1995, MacIntyre 1996) rather than an alternative limiting factor in vivo. However, there are 2 conditions where the light-saturated rate will not be limited by Rubisco activity under conditions that lead to photoinhibition or to feedback limitation. Photoinhibition occurs when the rate at which excitation energy is absorbed exceeds the ability of the cell to dissipate it, causing damage to the photosynthetic reaction centers and 
resulting in a reduction in the light-saturated rate of photosynthesis (Neale \& Richerson 1987). Feedback limitation of photosynthesis occurs when the limiting reaction in photosynthesis passes from carboxylation by Rubisco to utilization of triose phosphate and the subsequent regeneration of the substrate for carboxylation, ribulose bisphosphate (Sharkey et al. 1986. Sharkey 1990, Sassenrath-Cole et al. 1994). When feedback limitation occurs, Rubisco is down-regulated and the rate of photosynthesis declines. There is some indication that feedback limitation occurs in the data presented above and elsewhere (Macintyre et al. 1996): when a natural assemblage was dark-adapted and exposed to saturating irradiance, Rubisco activity was higher than before the dark period (Fig. 2) and the light-saturated rate of photosynthesis was higher than at steady state in Thalassiosira weissflogii (Fig. 4). If either photoinhibition or feedback limitation occurs under the mixing regime described below, the model will not be able to account for their effects and the second assumption, that the light-saturated rate of photosynthesis is determined by the maximum activity of Rubisco, will be invalid. However, we consider these to be second-order phenomena that act to modify the basic assumption relating light-saturated photosynthesis to maximum activity of Rubisco.

Research on vascular plants has shown that the rate-limiting step during photosynthetic induction is likely to be the light-sensitive activation of Rubisco (Woodrow \& Mott 1989, Lan et al. 1992, SassenrathCole et al. 1994). The time constants for photosynthetic induction described above are consistently shorter than those for Rubisco activation (Table 2). This may be due to the inadequacy of a first-order rate description (Eq. 2) to describe induction. Activation of Rubisco is biphasic (Woodrow \& Mott 1992), with an initial rapid activation of the effector Rubisco activase followed by activation of Rubisco itself. Further, the initial limiting step in induction may be the light-dependent regeneration of a pool of the substrate RuBP, after which photosynthesis is limited by activation of Rubisco (Sassenrath-Cole \& Pearcy 1992, Sassenrath-Cole et al. 1994). The kinetics of photosynthetic induction are, therefore, more complex than the simple description provided by Eq. (2). Regeneration of the RuBP pool is very rapid in comparison to activation of Rubisco, though, so we assume that the third assumption, that the kinetics of Rubisco's activation are a suitable proxy for photosynthetic induction, is generally valid.

There is oblique experimental support for the fourth assumption, that the kinetics of Rubisco's deactivation are a suitable proxy for photosynthetic deactivation. The initial rate of photosynthesis, which is a proxy for the state in which the photosynthetic apparatus is poised in darkness, shows a decline whose time course is consistent with that of deactivation of Rubisco (Fig. 4C).

The effect of mixing-induced fluctuations in irradiance can be considered by comparing steady-state and non-steady-state estimates of photosynthetic rates for a cell moving with a defined trajectory though the mixed layer. Here, and subsequently, the steady-state photosynthetic rate is defined as the rate measured in a $P I$ curve. When such a curve is used to estimate production in a water column, there is an implicit assumption that photosynthesis in the water column is at steady state. This is possible only if the photosynthetic response to a change in irradiance caused by mixing is more rapid than the change in irradiance itself (Lewis et al. 1984, Cullen \& Lewis 1988). In contrast, the nonsteady-state rate takes into account the lag in the photosynthetic response to a change in irradiance that occurs as the photosynthetic apparatus adjusts from one rate of photosynthesis to another. This is equivalent to estimating production from a photosynthesisirradiance-time curve. The lag in response is defined here in terms of the time constants of Rubisco activation and deactivation. The change in irradiance is imposed by a cell's trajectory as it is mixed through the photic zone.

\section{Defining a mixing-induced trajectory}

We assume that a cell's trajectory through the mixed layer can be based on a random-walk model. The cell is introduced into the middle of the mixed layer and its motion is defined by iterative moves, whose direction has an equal and random probability of being up or down. The change in depth in the discrete time interval $\Delta t$ is defined by a coefficient of diffusivity, $K_{z}$, with an equal probability of being up or down:

$$
z_{1}=z_{t-\Delta t} \pm \sqrt{2 K_{z} \Delta t}
$$

Diffusivity was assumed not to change with depth The mixed layer is bounded by 2 reflective surfaces, the surface and the depth of the mixed layer, $z_{m}$, so that there is no trapping at either interface. The depth through which the cell can move is limited such that $z_{\mathrm{m}} \geq z \geq 0$

\section{Steady-state rate of photosynthesis}

The steady-state estimate of photosynthesis is defined as the PIrelationship in Eq. (1), which can conveniently be rendered dimensionless with respect to irradiance by noting that the saturation parameter $I_{k}$ is equivalent to $P_{\mathrm{m}}^{\mathrm{chl}} / \alpha^{\mathrm{chl}}$ : 


$$
P^{c h l}=P_{\mathrm{m}}^{\mathrm{chl}}\left[1-\exp \left(\frac{-\alpha^{c h l} I}{P_{\mathrm{m}}^{\mathrm{chl}}}\right)\right]=P_{\mathrm{m}}^{\mathrm{chl}}\left[1-\exp \left(\frac{-I}{I_{k}}\right)\right]
$$

Eq. (6) can be rendered dimensionless with respect to photosynthesis by normalizing to the light-saturated rate, $P_{\mathrm{m}}^{\mathrm{chl}}$ :

$$
s P^{\bullet}=\frac{P^{\mathrm{chl}}}{P_{\mathrm{m}}^{\mathrm{chl}}}=1-\exp \left(\frac{-I}{I_{k}}\right)
$$

where ${ }^{s} p^{\cdot}$ is a dimensionless rate such that $0 \leq$ ${ }^{s} P^{\bullet} \leq 1$.

From Eq. (7), photosynthesis at depth $z$ is given by:

$$
{ }^{\mathrm{s}} P_{z}^{*}=1-\exp \left(\frac{-I_{z}}{I_{k}}\right)
$$

where $I_{z}$ is the irradiance at depth $z . I_{z}$ can be determined from the diffuse attenuation coefficient, $k$, and incident irradiance, $I_{0}$, as:

$$
I_{z}=I_{0} \exp (-k z)
$$

Eq. (8) can then be expressed as:

$$
{ }^{\mathrm{s}} P_{z}^{\bullet}=1-\exp \left(\frac{-I_{0} \exp (-k z)}{I_{k}}\right)
$$

The steady-state rate of photosynthesis can be calculated from Eq. (10) at any depth $z$, given values of $k$ and $I_{0} / I_{k}$. As a cell moves through the photic zone, the instantaneous rate of photosynthesis at time $t$ can be calculated from its trajectory (i.e. the variation of $z$ with $t$ ), given by Eq. (5), when the mixing depth, $z_{m}$, and diffusivity, $K_{z}$ are specified. The steady-state rate depends on the explicit assumption that the change in photosynthetic rate proceeds more rapidly than the mixing-induced change in irradiance (i.e. that photosynthetic response does not lag behind a change in irradiance).

\section{Non-steady-state rate of photosynthesis}

The non-steady-state rate of photosynthesis is determined by modulating Eq. (10) to account for the timedependent rates of activation and deactivation. Activity is treated as a dimensionless variable such that $0 \leq$ $A^{*} \leq 1$ (cf. Eq. 7). This assumes that the change in activity and the change in photosynthesis are linearly related (Fig. 1) and therefore saturate at the same irradiance, $I_{k}$. At steady-state:

$$
{ }^{\mathrm{s}} P^{\bullet}=A^{\bullet}=1-\exp \left(\frac{-I}{I_{k}}\right)
$$

The change in $A^{*}$ with time can be defined for each step in the trajectory, depending on the initial value of $A^{*}\left(A_{i-s}^{*}\right)$ and the value of ${ }^{s} P^{*}$ after the step $\left({ }^{s} P_{t}^{*}\right)$. Where s $P_{i}$ is higher than $A_{i-\Delta u}$ the activation state will increase. Where ${ }^{5} P_{i}$ is lower than $A_{i-\Delta t}$, the activation state will decrease. (Where ${ }^{s} P_{t}^{*}$ is equal to $A_{i-\Delta t}^{*}$ the activation state will not change.) Changes in the activation state are defined in dimensionless terms by normalizing Eqs. (3) and (4) to the range of activation, $A_{\mathrm{m}}^{\mathrm{chl}}-A_{\mathrm{d}}^{\mathrm{ch} !}$. For deactivation:

$$
A_{i}=\frac{A_{i}^{c h l}-A_{\mathrm{d}}^{c h l}}{A_{\mathrm{m}}^{c h l}-A_{\mathrm{d}}^{c h l}}=\exp \left(\frac{-t}{\tau_{\mathrm{d}}}\right)
$$

and for activation:

$$
A_{i}^{i}=\frac{A_{t}^{c h l}-A_{d}^{c h l}}{A_{m}^{c h l}-A_{d}^{c h l}}=1-\exp \left(\frac{-t}{\tau_{a}}\right)
$$

Thus for each step from $A_{t-\Delta t}^{*}$ to $A_{t}^{*}$, where ${ }^{s} P_{t}^{*}<A_{i-\Delta t}^{*}$

$$
A_{i}=A_{i-\Delta t}^{i} \exp \left(\frac{-\Delta t}{\tau_{\mathrm{d}}}\right)
$$

and for each step when ${ }^{s} P^{*}>A_{i-\Delta t}$ :

$$
A_{t}^{i}=A_{t-\Delta t}^{i}+\left(1-A_{i-\Delta t}^{i}\right)\left[1-\exp \left(\frac{-\Delta t}{\tau_{\mathrm{a}}}\right)\right]
$$

Note that an additional correction $\left(1-A_{i-\Delta t}^{*}\right)$ is introduced to constrain the dynamic range of activation state between the prior level $\left(A_{t-\Delta t}^{*}\right)$ and the maximum (1). Finally, the non-steady-state rate of photosynthesis, " $P$ ", depends on whether or not $A^{*}$ exceeds ${ }^{5} P^{*}$. For $A^{*}<{ }^{\mathrm{s}} P^{*}$ :

$$
{ }^{n} P^{*}=A^{*}
$$

and for $A^{\bullet}>{ }^{s} P^{\bullet}$

$$
{ }^{n} P^{\bullet}={ }^{\mathrm{s}} P^{\bullet}
$$

This relationship forces ${ }^{n} P^{\bullet} \leq{ }^{s} P^{\bullet}$, on the assumption that photosynthesis is limited by irradiance when Rubisco activation exceeds the steady-state condition. Embedded in this treatment is the assumption that there is no short-term increase in the light-saturated rate of photosynthesis above the steady-state rate. The model does not allow for any enhancement of photosynthesis above $P_{\mathrm{m}}^{\mathrm{chl}}$ that may arise if feedback limitation of photosynthesis or photoinhibition are alleviated under non-steady-state conditions. The deactivation of the photosynthetic apparatus has no instantaneous effect on photosynthetic rate, but determines the starting point from which it must be induced on the next increase in irradiance.

Achieved photosynthesis, the reduction caused by the decline in ${ }^{n} P^{*}$ relative to ${ }^{s} P^{*}$, is defined as the ratio of the integrals of ${ }^{n} P^{\bullet}$ and ${ }^{s} P^{\bullet}$ with respect to time:

$$
R^{\mathrm{n} / \mathrm{s}}=\frac{\int_{t=0}^{i=\infty} \mathrm{n} P^{\bullet}(t) \mathrm{d} t}{\int_{t=0}^{t=\infty}{ }^{s} P^{\bullet}(t) \mathrm{d} t}
$$




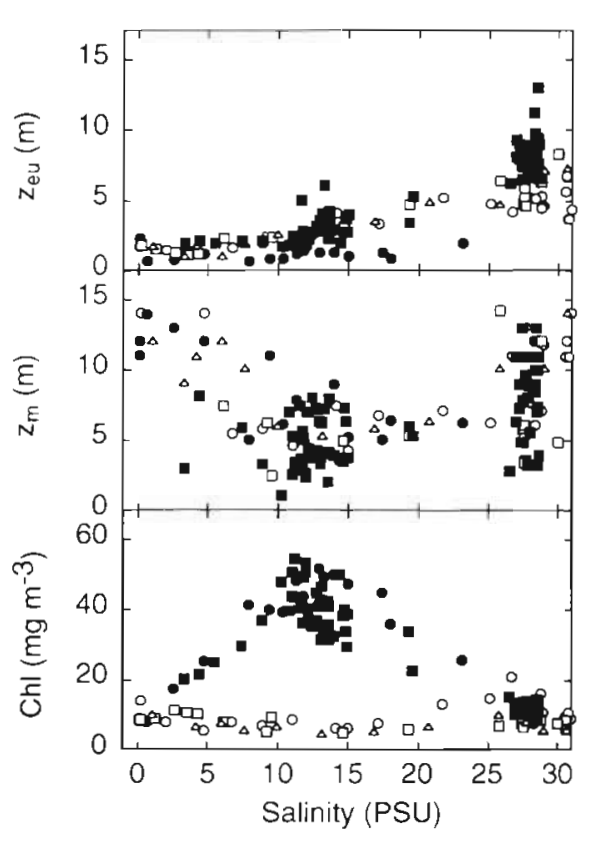

Fig. 5. Variation in the depths of the photic zone $\left(z_{\text {eu }}\right)$, mixed layer $\left(z_{m}\right.$, defined as the depth in which the density gradient is less than $1 \mathrm{~kg} \mathrm{~m}^{-3}$ ) and chlorophyll concentration (Chl) down the salinity gradient in Delaware Bay. Data were collected on 3 to 10 d cruises in August 1991 (O), July 1992 (ם), August $1993(\Delta)$, April $1992(\bullet)$ and April 1995 (ש). Note the pronounced spring bloom in the 5 to 20 PSU range

\section{Defining the input parameters}

The model requires specification of 7 input parameters: the attenuation coefficient $(k)$, the mixed depth $\left(z_{\mathrm{m}}\right)$, incident irradiance $\left(I_{0} / I_{k}\right)$, diffusivity $\left(K_{z}\right)$, and the time constants of activation and deactivation of Rubisco $\left(\tau_{a}\right.$ and $\left.\tau_{d}\right)$. The first 3 are set by the range of values measured in 2 estuaries: Delaware Bay, a relatively deep and weakly stratified estuary, and San Antonio Bay, a shallow lagoonal estuary. Values of the input parameters in the 2 bays are given in Table 3. The depths of the photic zone and mixed layer in
Delaware vary systematically along the salinity gradient (Fig. 5), so the representative data are for the range 5 to 20 PSU, the area in which the spring bloom develops (Pennock \& Sharp 1986). Lacking direct estimates of diffusivity, a range of values that is typical of weakly stratified estuaries $\left(1-10 \times 10^{-3} \mathrm{~m}^{2} \mathrm{~s}^{-1}\right.$, equivalent to $10-100 \mathrm{~cm}^{2} \mathrm{~s}^{-1}$; R. W. Garvine pers. comm.) were used. Because of the modest variability in the time constants for Rubisco activation and deactivation, $\tau_{a}$ and $\tau_{d}$ (Table 2), the mean values ( 3.7 and $16.5 \mathrm{~min}$ ) were used. To prevent errors from mismatched time scales, each simulation was run with a $2 \mathrm{~s}$ time step so that each step was much shorter than either time constant. Each simulation was allowed to run for 24 h $(43200$ iterations).

\section{MODEL PREDICTIONS}

Representative simulations are shown for the deep bay and shallow bay conditions (Fig. 6). Both were run under the same conditions of irradiance and diffusivity but differed in the attenuation coefficient and depth of the mixed layer (Table 3). The 2 simulations differ in the characteristic range and rate of change of irradiance, the driving force for the model. The deep bay simulation encompasses a wider range of irradiance because the mixed layer is equivalent to 11 optical depths $\left(z_{\mathrm{eu}}: z_{\mathrm{m}}=0.42\right.$ ), as compared to the 7 optical depths in the shallow bay simulation $\left(z_{\text {eu }}: z_{m}=0.66\right)$. However, the intrinsic rate of change is lower in the deep bay simulation because the photic zone is deeper ( $2.3 \mathrm{~m}$ vs $1.2 \mathrm{~m}$ for the shallow bay) although the diffusivity is the same. Transients across the photic zone are slower in the deep bay simulation than in the shallow bay, so that the photosynthetic response more closely approaches steady state.

The differences between the steady-state and nonsteady-state responses are shown in Fig. 7 There is a wider divergence between the two in the shallow bay

Table 3. Range of model input parameters as measured in Delaware Bay (DE, USA) and San Antonio Bay (TX, USA). Data are presented as the range (mean and SD in parentheses). Biomass and productivity data are shown for comparison. Productivity data are from ${ }^{4}$ Pennock \& Sharp (1986) and ${ }^{b}$ Maclntyre \& Cullen (1996). Deep Bay and Shallow Bay are the conditions chosen for the model simulations

\begin{tabular}{|lcccccc|}
\hline Location & $\begin{array}{c}k \\
\left(\mathrm{~m}^{-1}\right)\end{array}$ & $\begin{array}{c}z_{\mathrm{eu}} \\
(\mathrm{m})\end{array}$ & $\begin{array}{c}z_{\mathrm{m}} \\
(\mathrm{m})\end{array}$ & $I_{0} / I_{k}$ & $\begin{array}{c}\text { Chl } \\
\left(\mathrm{mg} \mathrm{m}^{-3}\right)\end{array} \begin{array}{c}\text { Productivity } \\
\left(\mathrm{g} \mathrm{C} \mathrm{m}^{-2} \mathrm{~d}^{-1}\right)\end{array}$ \\
\hline Delaware Bay & $0.8-6.4$ & $0.7-5.8$ & $1.1-12.1$ & $0.1-13.6$ & $4.3-62.7$ & $0.3-2.5^{\mathrm{a}}$ \\
& $(2.2,1.2)$ & $(2.1,1.2)$ & $(5.5,2.1)$ & $(5.8,4.2)$ & $(32.6,16.4)$ & $0.1-2.5^{\mathrm{b}}$ \\
San Antonio Bay & $0.7-15.3$ & $0.3-6.6$ & $1.3-2.5$ & $0.1-35.0$ & $3.2-47.8$ & $(15.3,10.4)$ \\
Deep Bay & $(4.2,2.7)$ & $(1.1,1.4)$ & $(1.8,0.3)$ & $(8.2,7.5)$ & 8 & \\
Shallow Bay & 2.0 & 2.3 & 5.5 & 8 & \\
\hline
\end{tabular}




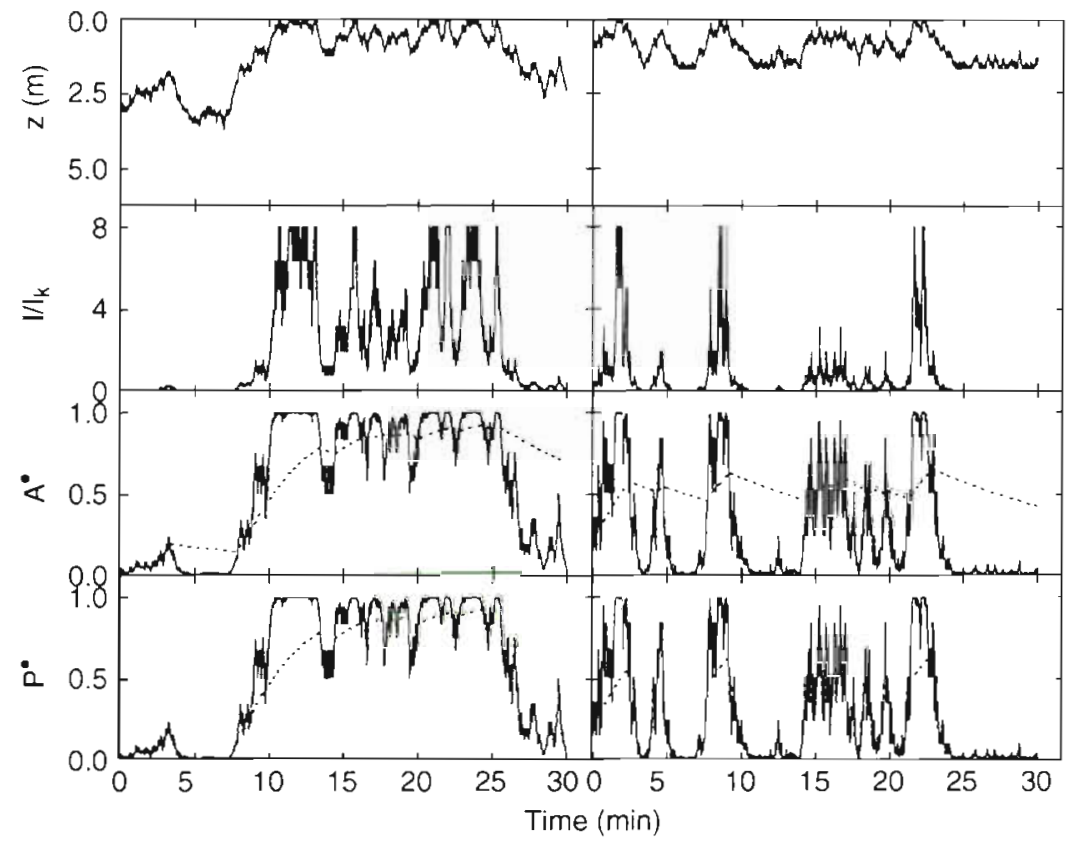

Fig. 6. Representative segments of model runs for the deep bay conditions (panels at left) and shallow bay conditions (panels at right). The panels show the trajectory of a cell $(z)$ over $30 \mathrm{~min}$, the irradiance that it experiences $\left(I_{0} / I_{k}\right)$, the steady-state and non-steady-state values of Rubisco activity ( $A^{*}$, solid and dashed lines, respectively) and the steady-state and non-steady-state values of photosynthesis $\left(P^{*}\right.$, solid and dashed lines, respectively). Deep bay conditions are: $z_{\mathrm{m}}=5.5 \mathrm{~m}$ and $k=2 \mathrm{~m}^{-1}$ Shallow bay conditions are: $z_{\mathrm{m}}=1.75 \mathrm{~m}$ and $k=$ $4 \mathrm{~m}^{-1}$ In both simulations $K_{z}=5 \times 10^{-3} \mathrm{~m}^{2}$ $\mathrm{s}^{-1} ; I_{0} / I_{k}=8 ; \tau_{\mathrm{d}}=16.5 \mathrm{~min}$ and $\tau_{\mathrm{o}}=3.7 \mathrm{~min}$

simulation than in the deep bay simulation. In the shallow bay, the envelope of non-steady-state responses does not reach the steady-state boundary where irradiance is higher than twice the saturating irradiance $\left(I_{0} / I_{k}>2\right)$. This divergence translates to a greater overestimate of production at high irradiance and a larger error in estimating areal production from steady-state rates than in the deep bay. Achieved photosynthesis is $88 \%$ of the steady-state prediction in the deep bay simulation and $82 \%$ of the prediction in the shallow bay simulation.
The model is driven by the range and rate of change of irradiance. It is instructive to compare the sensitivity of achieved photosynthesis to the parameters that define the rate at which irradiance changes (the attenuation coefficient, incident irradiance and diffusivity) and the parameters that define the cell's response to changes in irradiance (the time constants). Changing the value of one parameter while holding the others constant is not realistic. For instance, an increase in turbulence will result in an increase in turbidity in shallow water because of benthic resuspension and may result

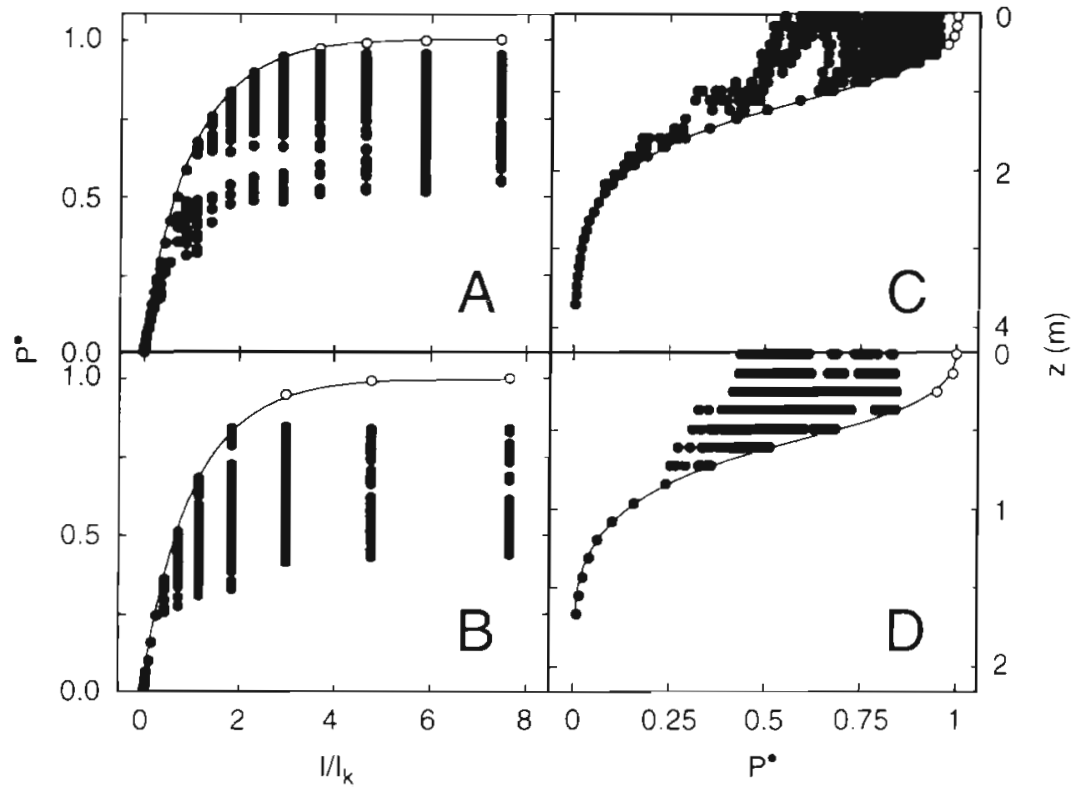

Fig. 7. Variation of steady-state $(0$, solid line $)$ and non-steady-state $(\bullet)$ rates of photosynthesis, $P^{*}$, predicted by the model under mean deep bay and shallow bay conditions as a function of irradiance, $I / I_{k}$, and depth, $z$ (A, C) Deep bay conditions. (B, D) Shallow bay conditions 
in a deepening of the mixed layer as density stratification is eroded. However, varying each parameter in turn does yield a better understanding of the sensitivity of the model, though not the interaction of its inputs. In the following sensitivity analyses, the deep bay and shallow bay differ in both the attenuation coefficient (and therefore the depth of the photic zone) and the depth of the mixed layer. The difference in the set parameters is designed to illustrate differences between characteristics of a shallow, turbid estuary and those of a relatively deep and clear estuary, rather than simply to compare a shallow with a deep estuary.

\section{Sensitivity to the attenuation coefficient}

The attenuation coefficient, $k$, was varied across the range of measured values (Table 3 ). Because the randomly varying trajectories of a cell in the model cause some variation in estimates of achieved photosynthesis between runs, the predictions from 10 model runs (each of 43200 iterations) were averaged for each input value. Achieved photosynthesis declined with an increase in attenuation (Fig. 8A), falling to 0.6 in the extreme case. There was a divergence between the simulations for the shallow bay and the deep bay. The range of irradiance experienced by the cell was higher in the deep bay than in the shallow bay (Fig. 8B), because of the deeper mixing, although the rate of change of irradiance was the same for a given value of attenuation. Achieved photosynthesis was lower in the deep bay because the wider range of irradiance corresponds to a wider range of activation states (Fig. 8C), hence a more pronounced lag in activating photosynthesis when the cell is mixed to the surface. Fig. $8 \mathrm{~A}$ also illustrates the effect of changing the depth of the mixed layer under given conditions of attenuation. Deeper mixing results in a decrease in achieved photosynthesis because the range of activation, and so the margin by which the photosynthetic apparatus must 'catch up' increases.

\section{Sensitivity to irradiance}

Achieved photosynthesis was less sensitive to changes in irradiance than to changes in attenuation, when each was varied over its observed range (the minimum value was 0.81 ; Fig. 9A) and was consistently lower in the shallow bay. In both simulations, there was a minimum at intermediate irradiance. The reason for this lies in the range of irradiance experienced in each simulation, which determines the range over which Rubisco activity and therefore the photosynthetic rate must change in a given time step in the model run. If the range is small, the rate at which the photosynthetic apparatus responds to a change in irradiance approaches the rate at which irradiance changes. Photosynthesis reaches $99 \%$ of saturation when $I_{0} / I_{k}=4.6$. As irradiance increases up to this point, the range of photosynthetic rates in the water column increases and the effect of a lag in response becomes more pronounced (Fig. 9B, C). There is little change in achieved photosynthesis at higher irradiances in the deep bay simulation because the water column encompasses the entire range of activation states (Fig. 9B). The slight increase in achieved photosynthesis occurs because more of the water column is at saturating irradiance and cells mixed toward the
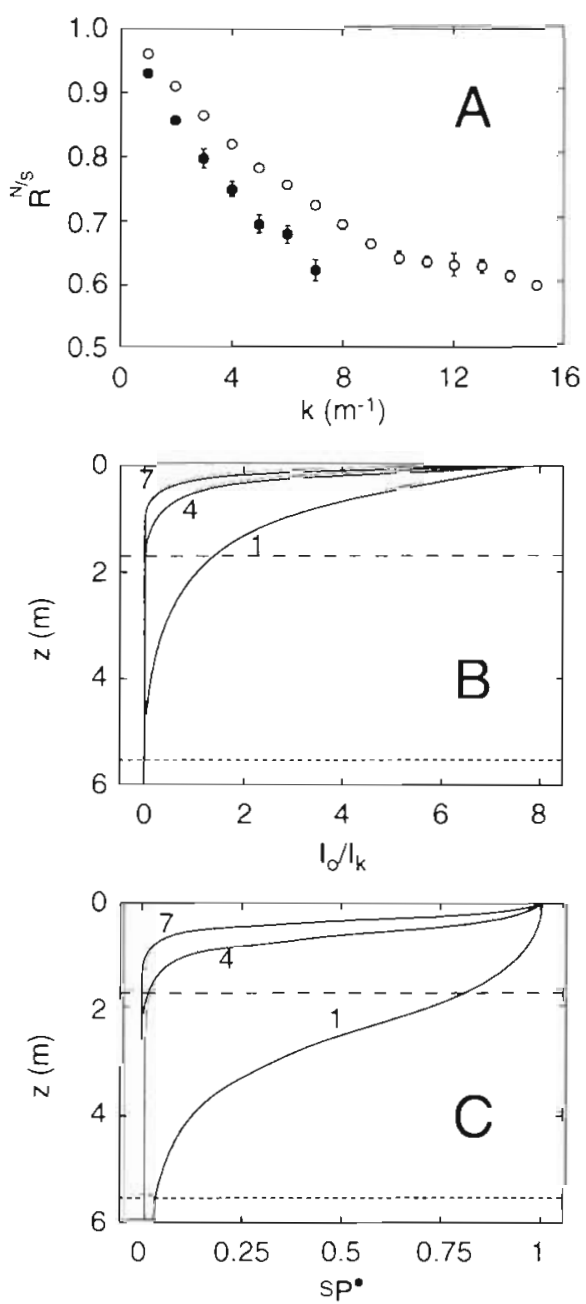

Fig. 8. (A) Variation in achieved photosynthesis, $R^{n / s}$, with attenuation, $k$, for deep bay $(\bullet)$ and shallow bay (O) simulations. Each datum is the mean \pm SE of 10 model runs. (B) Variation of irradiance, $I_{0} / I_{k}$, with depth, $z$, for $k=1,4$ and $7 \mathrm{~m}^{-1}$. (C) Variation of steady-state photosynthesis, ${ }^{5} p^{*}$, with depth, $z$, for $k=1,4$ and $7 \mathrm{~m}^{-1}$ The dotted and dashed line are the mixing depths for the deep bay and shallow bay simulations 

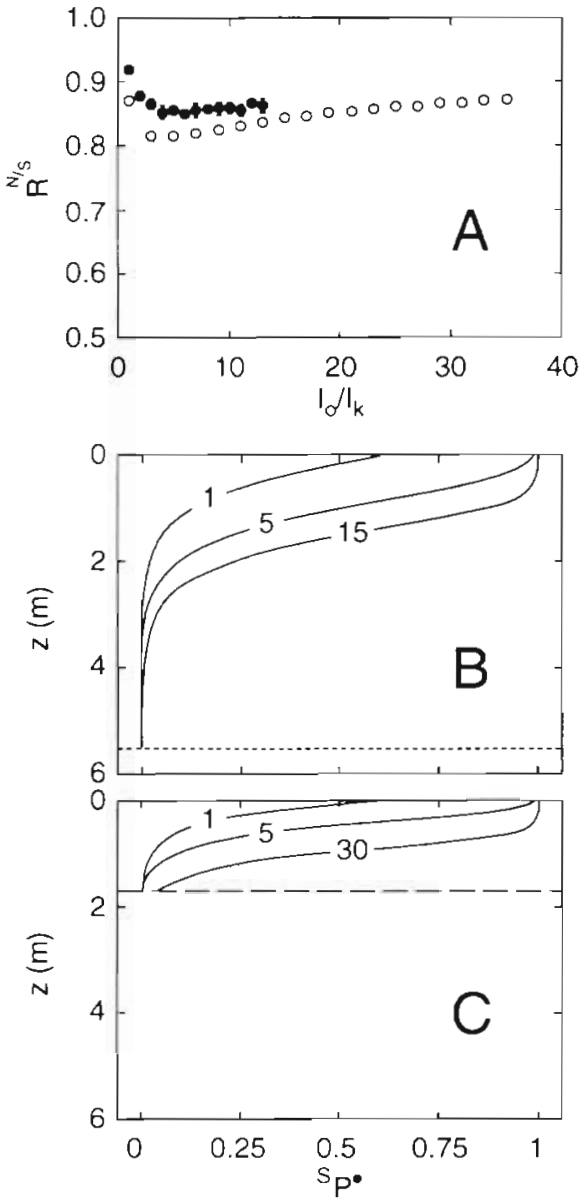

Fig. 9. (A) Variation in achieved photosynthesis, $R^{n / s}$, with irradiance, $I_{0} / I_{k}$, for deep bay $(\bullet)$ and shallow bay (o) simulations. Each datum is the mean $\pm \mathrm{SE}$ of 10 model runs. (B) Variation of steady-state photosynthesis, ${ }^{s} P^{*}$, with depth, $z_{1}$ under deep bay conditions for $I_{0} / I_{k}=1,5$ and 15 . The dotted line is the depth of the mixed layer. (C) Variation of steady-state photosynthesis, ${ }^{s} P^{*}$, with depth, $z$, under shallow bay conditions for $I_{0} / I_{k}=1,5$ and 30 . The dashed line is the depth of the mixed layer

surface are more likely to be acclimated to saturating irradiance. The more pronounced increase in achieved photosynthesis at higher irradiances in the shallow bay simulation occurs because of the shallow mixed depth. An increase in irradiance through the water column results in a smaller range of activation states (Fig. 9C). The lag imposed by activation of Rubisco therefore becomes less pronounced

\section{Sensitivity to diffusivity}

When diffusivity was varied over the range expected in a weakly stratified estuary, achieved photosynthesis declined with increasing turbulence (Fig. 10). The
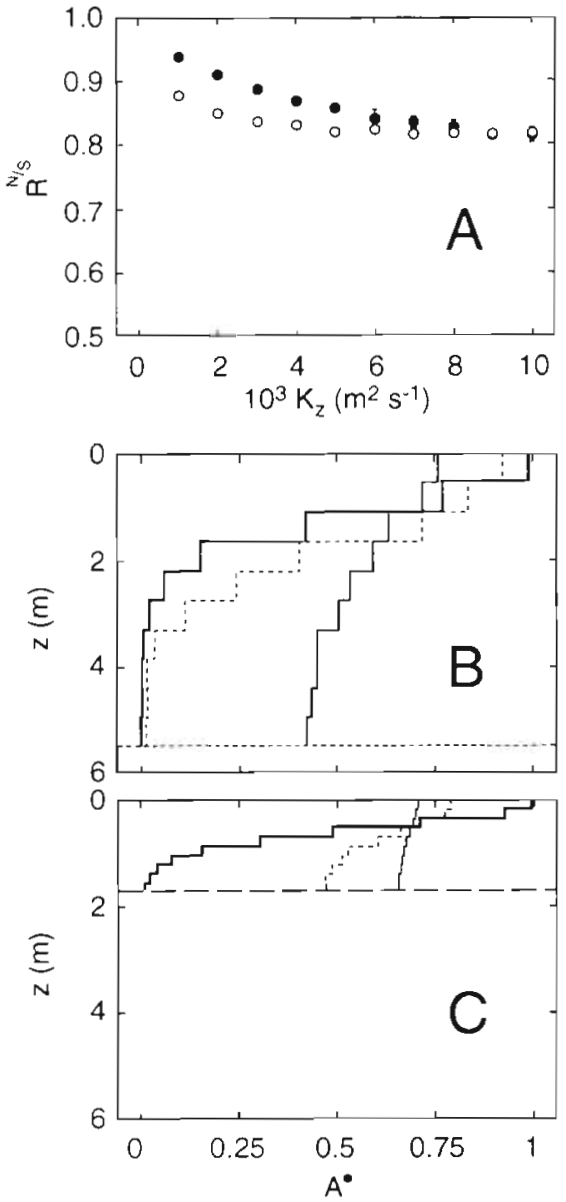

Fig. 10. (A) Variation in achieved photosynthesis, $R^{n / s}$, with diffusivity, $K_{z}$, for deep bay ( $\bullet$ ) and shallow bay (o) simulations. Each datum is the mean \pm SE of 10 model runs. (B) Variation of activation state, $A^{*}$, with depth, $z$, under deep bay conditions. The dotted line is the depth of the mixed layer. (C) Variation of activation state, $A^{*}$, with depth, $z$, under shallow bay conditions. The dashed line is the depth of the mixed layer. Predictions of $A^{*}$ from one model run were grouped into 10 bins and averaged. In (B) and (C), data are for steady state (heavy solid line) and non-steady state at $K_{z}=1$ and $10 \times$ $10^{-3} \mathrm{~m}^{2} \mathrm{~s}^{-1}$ (dotted and thin solid lines, respectively)

range of achieved photosynthesis (minimum of 0.82) was comparable to that observed over the range of irradiance and less than that over the range of attenuation. There was a systematic difference between the deep bay and shallow bay simulations. The initial decline was more rapid for the shallow bay than for the deep bay but there was little further reduction beyond the mid-range of diffusivity. In the deep bay, achieved photosynthesis declined over the entire range of diffusivity. This arises because of the characteristic rate of change of irradiance under the 2 conditions. As irradiance varies more rapidly, the cell's ability to track changes declines and the activation state becomes 
more homogenous through the water column. The rate of change is higher in the shallow bay because of its higher turbidity, as reflected in profiles of the activation state (Fig. 10B, C).

\section{Sensitivity to the time constants of activation and deactivation}

The time constants of activation and deactivation, $\tau_{a}$ and $\tau_{d}$, showed relatively little variability between species (Table 2). The sensitivity of achieved photosynthesis to changes in the response time of the photosynthetic apparatus was examined by running simulations under both deep bay and shallow bay conditions using values of $\tau_{\mathrm{a}}$ and $\tau_{\mathrm{d}} \pm 2$ standard deviations from the pooled mean (Fig. 11). Achieved photosynthesis varied with the rate of deactivation, but changes in $\tau_{d}$ resulted in only modest changes, except where the rate of activation was high. Achieved photosynthesis was more sensitive to the rate of activation, with which it is inversely correlated. When the photosynthetic apparatus responds rapidly to an increase in irradiance (when $\tau_{\mathrm{a}}$ is low), non-steady-state photosynthesis approaches the steady-state rate and achieved photosynthesis approaches unity. Conversely, when the response is slow (when $\tau_{a}$ is high), the lag in non-steady-state photosynthesis is more pronounced and achieved photosynthesis declines. The sensitivity to the rate of acti-

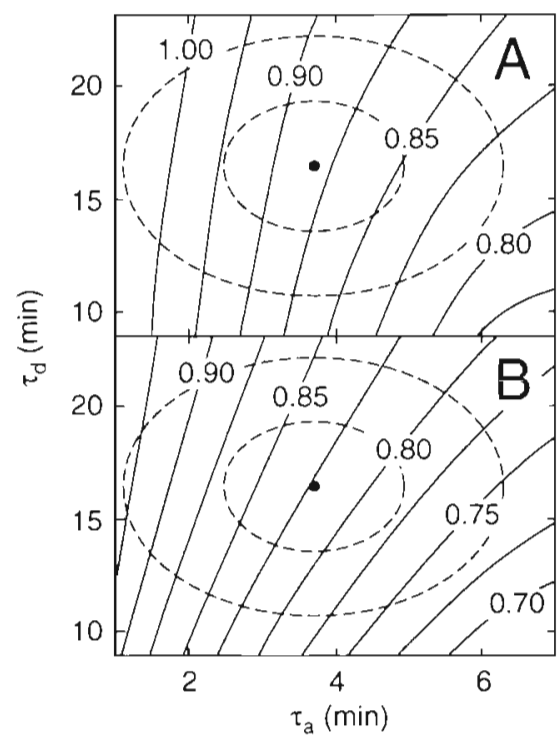

Fig. 11 Variation in achieved photosynthesis, $R^{n / s}$, with the time constants of deactivation and activation, $\tau_{\mathrm{d}}$ and $\tau_{\mathrm{a}}$, for (A) deep bay and (B) shallow bay conditions. Contours are of $R^{n / 5}$ and were derived by varying $\tau_{d}$ and $\tau_{a}$ in increments of $1 \mathrm{~min}$. Mean values of $\tau_{d}$ and $\tau_{a}$. The concentric ellipses are the boundaries of 1 and 2 standard deviations from the mean vation is damped when the rate at which the photosynthetic apparatus is deactivated is slow because the photosynthetic apparatus is more likely to be overactivated at low irradiance. The sensitivity of achieved photosynthesis to variation in the time constants is more pronounced when the rate of change in irradiance is high (i.e. in the shallow bay condition)

\section{COMPARISON OF MODEL PREDICTIONS WITH PUBLISHED RESULTS}

Several studies have compared production in static incubations with production in incubations that simulate mixing in estuarine waters. The predictions of the model can be compared with the findings of 3 of them. The first study (Yoder $\&$ Bishop 1985) was conducted in Wassaw Sound, Georgia, USA. The mixed layer was $5 \mathrm{~m}$ deep and the attenuation coefficient ranged between 0.95 and $2.9 \mathrm{~m}^{-1}$ (mean, $1.5 \mathrm{~m}^{-1}$ ), comparable with the deep bay conditions. Bottles were incubated for $3.5 \mathrm{~h}$ at fixed depths or stepped through the water column at rates of $1,2.5$ and $5 \mathrm{~m}$ every $10 \mathrm{~min}$, comparable to diffusivities of $0.8,5.2$ and $20.8 \times 10^{-3} \mathrm{~m}^{2} \mathrm{~s}^{-1}$, a wider range than tested here. The PI relationship from the fixed-depth bottle incubations was used to estimate production in the moving bottles, based on the irradiance to which they had been exposed. Individual observations of achieved photosynthesis (i.e. the ratio of predicted to observed production) varied between 0.7 and 1.7. A regression of predicted on observed production had a slope of $1.11 \pm 0.08\left(R^{2}=0.89\right)$, equivalent to mean achieved production of 0.90 . When 1 of the 8 sets of experiments was omitted, the slope fell to $1.02 \pm 0.06\left(R^{2}=0.95\right)$, equivalent to achieved production of unty. The model was run over the reported ranges of attenuation and diffusivity and predicted achieved photosynthesis of 0.74 to 0.98 (Fig. 12A). These estimates fall within the range of observed data and, at the lowest diffusivity, within 1 standard error of the reported slope. However, the model underestimated production when compared with the restricted data set, which comprised 41 of the 47 observations.

The second study (Mallin \& Paerl 1992) was conducted in the Neuse River Estuary, North Carolina. The bay was well mixed to the bottom, at $3.4 \mathrm{~m}$, and the attenuation coefficient ranged between 0.86 and $1.4 \mathrm{~m}^{-1}$. The mixing depth was therefore intermediate between the deep bay and shallow bay conditions but the water was much clearer than in either. Samples were incubated under simulated in situ conditions under static or fluctuating irradiance. The simulated mixing had a 25 min cycle, comparable to a diffusivity of $30.8 \times 10^{-3} \mathrm{~m}^{2} \mathrm{~s}^{-1}$. Static incubations showed pronounced surface photoinhibition and in 3 of the 7 comparisons, there was a significant increase 


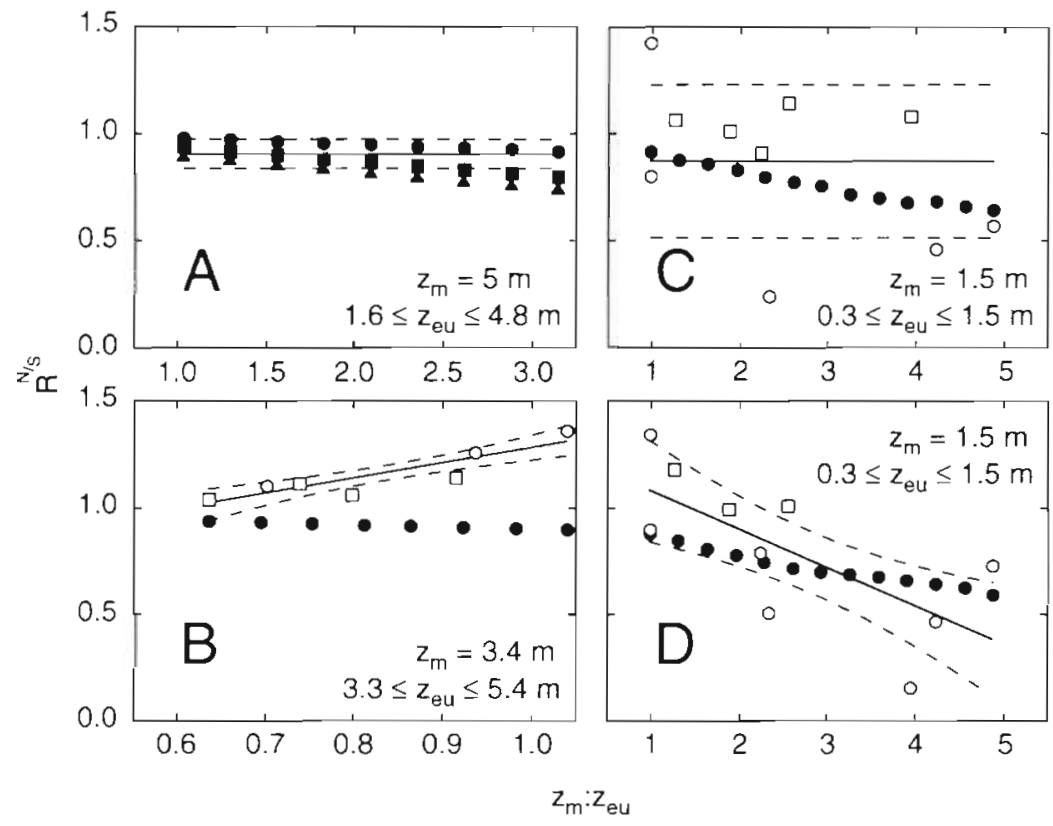

Fig. 12. Comparison of the model's predictions of achieved photosynthesis, $R^{n / s}$, as a function of turbidity, $z_{\mathrm{m}}: z_{\mathrm{eu}}$, with published data. Note the different ranges of $z_{\mathrm{m}}: z_{\mathrm{eu}}$ between data sets. Input values of $z_{\mathrm{m}}$ and $z_{\mathrm{eu}}$ are shown on each panel. (A) Comparison with data of Yoder \& Bishop (1985). Predictions were calculated for diffusivities of $0.9 \times 10^{-3}(\bullet), 5.2 \times 10^{-3}$ (ש) and $20.9 \times 10^{-3}$ (4) $\mathrm{m}^{2} \mathrm{~s}^{-1}$ The solid line is the slope of a regression of observed on predicted productivity. Dashed lines are \pm 1 SE. (B) Comparison with data of Mallin \& Paerl (1992). Observed values of achieved photosynthesis that are (O) and are not () significantly different from unity are compared with predictions (•) that were calculated for diffusivities of $30.8 \times 10^{-3} \mathrm{~m}^{2} \mathrm{~s}^{-1}$. The solid line is the slope of a regression of observed $R^{\mathrm{n} / \mathrm{s}}$ on $z_{\mathrm{m}}: z_{\mathrm{el}}$. Dashed lines are $95 \%$ confidence limits of the regression. (C) Comparison with data of Randall \& Day (1987). Observed values of achieved photosynthesis that are $(0)$ and are not (a) significantly different from unity are compared with predictions $(\bullet$ that were calculated for diffusivities of $1.25 \times 10^{-3} \mathrm{mn}^{2} \mathrm{~s}^{-1}$ The solid line is the mean value of observed $R^{11 / s}$. Dashed lines are \pm 1 SD. (D) Comparison with data of Randall \& Day (1987). Observed values of achieved photosynthesis that are (0) and are not (ㅁ) significantly different from unity are compared with predictions ( $\bullet$ ) that were calculated for diffusivities of $2.5 \times 10^{-3} \mathrm{~m}^{2} \mathrm{~s}^{-1}$ The solid line is the slope of a regression of observed $R^{\mathrm{n} / \mathrm{s}}$ on $z_{\mathrm{m}}: z_{\mathrm{eu}}$. Dashed lines are $95 \%$ confidence limits of the regression. All simulations were calculated with $I_{0} / I_{k}=8$

1.3 and $2.5 \times 10^{-3} \mathrm{~m}^{2} \mathrm{~s}^{-1}$. When bottles were cycled every 60 min, there was no significant difference in production between static and cycled incubations in 5 of 10 experiments. There was no significant relationship between achieved photosynthesis and turbidity (Fig. 12C). The predictions of the model, achieved photosynthesis of 0.65 to 0.92 , fell within 1 standard deviation of the mean of the observed values. When bottles were cycled every $30 \mathrm{~min}$, there was a significant difference in production between static and cycled incubations in 7 of 10 experiments. Production in the cycled bottles was lower and decreased as turbidity increased. The model's predictions of achieved photosynthesis showed the same pattern, declining from 0.89 to 0.59 (Fig. 12D) over the same range of turbidity. The predictions fell within the $95 \%$ confidence limits of the regression, aIthough there was a difference in the trends.

\section{DISCUSSION}

The model predicts that the decline in achieved photosynthesis due to mixing will be more pronounced in a shallow and turbid estuary than in a deeper and clearer one because the lag in nonsteady-state photosynthesis is most pronounced at high turbidity, Varying the remaining input parameters (mixing depth, irradiance and diffusivity) has comparatively little effect. The model predicts that there will be relatively little reduction in achieved photosynthesis at

in production with mixing. Achieved production increased with turbidity, as expressed by the ratio of mixing depth to photic depth, with a peak value of 1.36 (Fig. 12B). In contrast, the model predicted a decline with turbidity from 0.94 to 0.87 over the same range. The predictions of the model fell outside the $95 \%$ confidence limits of the reported data.

The third study (Randall \& Day 1987) was conducted in Fourleague Bay, Louisiana. The bay was well mixed and shallow (average depth $1.5 \mathrm{~m}$ ) and the attenuation coefficient ranged between 3 and $11 \mathrm{~m}^{-1}$, comparable with the shallow bay conditions. Bottles were incubated at the surface, at 1 Secchi depth, at 2 Secchi depths and at the bottom or were cycled through the depths in 60 and 30 min cycles. This is comparable to diffusivities of low irradiance (values of $I_{0} / I_{k}$ that are less than 5 ) but these are conditions that are usually found only on very overcast days or at the beginning and end of the photoperiod. The wide ranges reported for Delaware Bay and San Antonio Bay in Table 3 are due to a high frequency of sampling at dawn and dusk. There is likely to be a strong secondary effect of changes in diffusivity, particularly in shallow waters, because high turbulence can result in benthic resuspension and an increase in turbidity. Varying the biological response time by more rapid activation or slower deactivation ameliorated the reduction in achieved photosynthesis. The change was relatively small. changes of 1 standard deviation from the mean caused a difference in achieved photosynthesis of ca 0.03 for mean values of 0.80 to 0.92 . 
It is important to distinguish between the error in estimating production from steady-state rates of photosynthesis and the magnitude of the estimate per se. The conditions under which the most extreme reductions in achieved photosynthesis occur, the high turbulence and turbidity associated with resuspension in a shallow bay, are also the conditions under which production is lowest. While the magnitude of the error is greatest under these conditions, and might be as high as a $100 \%$ overestimate of production, production itself is likely to be only 30 to $45 \%$ of production under normal (mean) conditions. Even so, the model predicts that productivity estimates based on steady-state rates of photosynthesis will overestimate production by 14 and $22 \%$ under average conditions in the 2 systems. Before accepting these predictions, there are 3 other factors that should be considered: the vertical variation of diffusivity, the effect of mixing on alleviating photoinhibitory stress, and the effect of mixing in reducing feedback limitation of photosynthesis.

The changes in irradiance predicted by the model were based on the assumption that diffusivity does not vary with depth, an assumption unlikely to hold for either the deep or the shallow bay. In both bays there will be mid-depth maxima in diffusivity because of shear associated with the bottom, or, where it exists, a pycnocline, and with the air-water interface (Bowden 1977). The practical outcome of this is that cells will tend to be trapped at the bottom and surface of the mixed layer and the rate of change in irradiance in both regions will be reduced. Where much of production is light-saturated, the error in estimating production from steadystate rates of photosynthesis will be reduced.

Trapping at the surface can also cause a reduction in production where cells remain at high irradiance for long enough to experience photoinhibitory irradiances. Such surface photoinhibition is most likely to accur in situations where there is diel stratification of a water column (Vincent et al. 1984, Neale \& Richerson 1987), but photoinhibition has been inferred to occur from fluorescence in surface waters of the representative deep bay, Delaware Bay (T. M. Kana, R. J. Geider \& H. L. MacIntyre unpubl. data), and throughout the water column in the well-mixed and turbid waters of the representative shallow bay, San Antonio Bay (MacIntyre \& Cullen 1996). Where production estimates from moving and fixed-depth incubations have been compared, the enhanced production seen in the moving bottles has been attributed to artefactual surface photoinhibition in the control, fixed-depth incubations (Marra 1978a, b, Randall \& Day 1987, Mallin \& Paerl 1992). The increase in achieved photosynthesis with turbidity in Mallin \& Paerl's (1992) data (Fig. 12B) is counter-intuitive: photoinhibition would usually be most pronounced in the clearer water. The trend may have arisen because the assemblages at high turbidity were acclimated to lower irradiance before the incubation and so more prone to photoinhibition. The model does not account for photoinhibition, although it could be incorporated by adding an irradiance-weighted term to do so (cf. Pahl-Wostle \& Imboden 1990, Franks \& Marra 1994).

Where there is no surface inhibition in the fixeddepth bottles, there may be no difference between the static and mixed incubations (Yoder \& Bishop 1985). The reduction in production in mixed bottles described by Randall \& Day (1987) occurred even though there was surface inhibition in half of the static incubations. These data were collected from very turbid waters and the authors attributed the reduction at high turbidity in the rapidly mixed samples to limitation by induction, the mechanism on which our model is based. The difference in the trends between the model's predictions and the experimental data may have been due to the photoinhibition observed in the controls, if there was a higher likelihood of photoinhibition at low turbidity. The good agreement between the model's prediction and Randall \& Day's (1987) data suggest that the model may have some validity.

Even where photoinhibition has not been found to be an influence in comparisons between fixed-depth and moving bottle incubations (Marra 1978b, Yoder \& Bishop 1985), there may be differences between the treatments. Estimates of the light-saturated rate of photosynthesis are sensitive to the duration of exposure, declining even during incubations of less than $1 \mathrm{~h}$ in length (Marra 1978b). Conversely, the lightsaturated rate of photosynthesis rises after short (25 to 70 min) dark adaptation (Fig. 4), which we have argued previously is due to the alleviation of feedback limitation of photosynthesis (MacIntyre et al. 1996). If the onset of feedback limitation is prevented by alternation of saturating irradiance and low irradiance or darkness, as occurs during mixing, then the light-saturated rate of photosynthesis can be higher in mixed than in static incubations, without any photoinhibitory decrease in production in the static controls. This could account for the tendency of the model to underestimate the achieved photosynthesis described by Yoder \& Bishop (1985). In that study, the moving bottle incubations were switched between the bottom and surface $k<1$ and $100 \%$ of incident irradiance, respectively) every $10 \mathrm{~min}$ at the highest diffusivity. If feedback limitation does not occur for the first $10 \mathrm{~min}$ in saturating irradiance (cf. Fig. 4), this will cause an enhancement that could offset the decline in achieved photosynthesis predicted by the model. Under these circumstances, mixing would enhance photosynthesis without any alleviation of photoinhibition, as suggested by Marra (1978b). While the model does not account for a reduc- 
tion in the steady-state rate of photosynthesis due to feedback limitation, it could be modified to do so by incorporating time constants for the recovery and decline of the light-saturated rate of photosynthesis. Such a model would be functionally similar to the model proposed by Pahl-Wostle \& Imboden (1990).

\section{SUMMARY}

We present a simple, mechanistic model that describes the effect of mixing on achieved photosynthesis under conditions typical of estuarine systems. The model is based on the activation and deactivation of Rubisco and predicts that a decline in non-steady-state photosynthesis will be greatest in turbid, rapidly mixed waters and will be more severe in deep than shallow waters. The predictions of the model compare favorably with published data in a shallow, turbid bay, the conditions under which the model predicts the greatest reduction of photosynthesis. The model tends to overestimate the negative effect of mixing in a deeper and clearer bay, possibly because of a compensating increase in production due to a reduction in feedback limitation of photosynthesis. The mechanisms included in the model do not include photoinhibition, so the model cannot account for any enhancement of production by mixing that was caused by photoinhibition in static controls.

Acknowledgements. We thank Tim Deering and the captain and crew of the RV 'Cape Henlopen' for their help in collecting the field data. Bill Henley and 2 anonymous revieweres provided valuable criticism of the manuscript. This work was supported by the DoE Grant DE-FG02-93ER61695 and NSF Grant OCE-9301768. This manuscript was part of a dissertation submitted by H.L.M. in partial fulfillment of the requirements for the degree of Doctor of Philosophy at the University of Delaware.

\section{LITERATURE CITED}

Anderson FE (1976) Rapid settling rates observed in sediments resuspended by boat waves over a tidal flat. Neth $\mathrm{J}$ Sea Res 10:44-58.

Arfi R, Guiral D, Bouvy M (1993) Wind induced resuspension in a shallow tropical lagoon. Estuar Coast Shelf Sci 36 $587-604$

Barkmann W, Woods JD (1996) On using a Lagrangian model to calibrate primary production determined from in vitro incubation measurements. J Plankton Res 18:767-788

Björkman O (1981) Responses to different quantum flux densities. In: Lange OL, Nobel PS, Osmond CB, Ziegler $\mathrm{H}$ (eds) Physiological plant ecology. 1. Responses to the physical environment. Springer-Verlag, Berlin, p 57-107

Bowden KF (1977) Geophysics, estuaries and the environment. National Research Council

\section{Appendix 1}

Photosynthetic induction is assumed to follow first-order kinetics:

$$
\frac{\mathrm{d} C^{\mathrm{chl}}}{\mathrm{d} t}=P_{1}^{\mathrm{chl}}+\left(V_{\mathrm{m}}^{\mathrm{chl}}-P_{1}^{\mathrm{chi}}\right)\left[1-\exp \left(\frac{-t}{\tau_{\mathrm{p}}}\right)\right]
$$

Integrating between the time that lights are turned on ( $t=$ $0)$ and time $T$ is given by:

$$
C^{c h l}(T)=\int_{0}^{T}\left\{P_{1}^{c h l}+\left(V_{\mathrm{mi}}^{\text {chl }}-P_{i}^{\mathrm{chl}}\right)\left[1-\exp \left(\frac{-t}{\tau_{\mathrm{p}}}\right)\right]\right\} \mathrm{d} t
$$

Algebraic rearrangement of Eq. (A2) leads to:

$$
C^{\mathrm{chl}}(T)=\int_{0}^{T}\left[V_{\mathrm{m}}^{\mathrm{chl}}-\left(V_{\mathrm{m}}^{\mathrm{chl}}-P_{\mathrm{l}}^{\mathrm{chl}}\right) \exp \left(\frac{-t}{\tau_{\mathrm{p}}}\right)\right] \mathrm{d} t
$$

The solution of Eq. (A3) is:

$$
C^{c h l}(T)=\left.V_{m}^{c h l} t\right|_{0} ^{T}+\left.\tau_{p}\left(V_{m l}^{c h l}-P_{\mathrm{l}}^{c h i}\right) \exp \left(\frac{-t}{\tau_{\mathrm{p}}}\right)\right|_{0} ^{T}
$$

Note that the symbol $\left.\right|_{0} ^{T}$ designates an operation whereby the term to the left of the symbol is evaluated at $t=T$ and $t=0$, and the difference between these terms is taken. Thus:

$$
\left.V_{\mathrm{m}}^{\text {chl. }} \cdot t\right|_{0} ^{T}=V_{\mathrm{m}}^{\text {chl }} \cdot T=V_{\mathrm{m}}^{\mathrm{chl}} \cdot 0=V_{\mathrm{m}}^{\mathrm{enl}} \cdot T
$$

and,

$$
\left.\exp \left(\frac{-t}{\tau_{\mathrm{p}}}\right)\right|_{\hat{B}} ^{T}=\exp \left(\frac{-T}{\tau_{\mathrm{p}}}\right)-\exp (0)=-\left[1-\exp \left(\frac{-T}{\tau_{\mathrm{p}}}\right)\right]
$$

Thus the solution of Eq. (A2) is

$$
C^{c h l}(T)=V_{m}^{c h l} t T-\tau_{p}\left(V_{m}^{c h l}-P_{i}^{c h l}\left[1-\exp \left(\frac{-T}{\tau_{p}}\right)\right]\right.
$$

Boyer JN, Christian RR, Stanley DW (1993) Patterns of phytoplankton primary productivity in the Neuse River estuary, North Carolina, USA. Mar Ecol Prog Ser 97:287-297

Bush KJ, Sweeney BM (1.972) The activity of ribulose diphosphate carboxylase in extracts of Gonyaulax polyedra in the day and the night phases of the circadian rhythm of photosynthesis. Plant Physiol 50:446-451

Cadée GC, Hegeman J (1974) Primary production of phytoplankton in the Dutch Wadden Sea. Neth $J$ Sea Res 8 240-259

Cloern JE, Powell TM, Huzzey LM (1989) Spatial and temporal variability in south San Francisco Bay (USA). II. Temporal changes in salinity suspended sediments and phytoplankton biomass and productivity over tidal time scales. Estuar Coast Shelf Sci 28:599-613

Cole B, Cloern JE (1984) Significance of biomass and light availability to phytoplankton productivity in San Francisco Bay. Mar Ecol Prog Ser 17:15-24

Cullen JJ, Lewis MR (1988) The kinetics of algal photoadaptation in the context of vertical mixing. J Plankton Res 10: 1039-1063

Denman KL, Marra J (1986) Modelling the time dependent photoadaptation of phytoplankton to fluctuating light. In: Nihoul JCJ (ed) Marine interfaces ecohydrodynamics. Elsevier, Amsterdam, p 341-359

Franks PJS, Marra J (1.994) A simple new formulation for phytoplankton photoresponse and an application in a wind-driven mixed-layer model. Mar Ecol Prog Ser 111 $143-153$ 
Fréchette M, Legendre L (1978) Photosynthèse phytoplanctonique: réponse à un stimulus simple imitant les variations rapides de la lumière engendrées par les vagues. J Exp Mar Biol Ecol 32:15-25

Gabrielson JO, Lukatelich RJ (1985) Wind-related resuspension of sediments in the Peel-Harvey estuarine system. Estuar Coast Shelf Sci 20:135-145

Gallegos CL, Platt T (1982) Phytoplankton production and water motion in surface mixed layers. Deep Sea Res 29 $65-76$

Garrad PN, Hey RD (1987) Boat traffic, sediment resuspension and turbidity in a broadland river. J Hydrobiol 95: $289-297$

Glover HE, Morris I (1979) Photosynthetic carboxylating enzymes in marine phytoplankton. Limnol Oceanogr 24 $510-519$

Guillard RRL (1975) Culture of phytoplankton for feeding marine invertebrates. In: Smith WL, Chanley $\mathrm{MH}$ (eds) Culture of marine invertebrate animals. Plenum Publishing Co, New York, p 108-132

Joint IR, Pomeroy AJ (1981) Primary production in a turbid estuary. Estuar Coast Shelf Sci 13:303-316

Kirkpatrick GJ, Curtin TB, Kamykowski D. Feezor MD, Sartin MD, Reed RE (1990) Measurement of photosynthetic response to euphotic zone physical forcing. Oceanography 3:18-22

Kromkamp J, Limbeek M (1993) Effect of short-term variation in irradiance on light harvesting and photosynthesis of the marine diatom Skeletonema costatum: a laboratory study simulating vertical mixing. J Gen Microbiol 139 : $2277-2284$

Lan Y, Woodrow IE, Mott KA (1992) Light-dependent changes in ribulose bisphosphate carboxylase activase activity in leaves. Plant Physiol 99:304-309

Lewis MR, Cullen JJ, Platt T (1984) Relationships between vertical mixing and photoadaptation of phytoplankton: similarity criteria. Mar Ecol Prog Ser 15:141-149

Lewis MR, Smith JC (1983) A small-volume short-incubationtime method for measurement of photosynthesis as a function of incident irradiance. Mar Ecol Prog Ser 13: $99-102$

Litaker W, Duke CS, Kenney BE, Ramus J (1987) Short-term environmental variability and phytoplankton abundance in a shallow tidal estuary. 1. Winter and summer. Mar Biol 96:115-121

Maclntyre HL (1996) Photosynthesis in variable light fields: regulation of Rubisco activity. PhD dissertation, University of Delaware, Newark

Maclntyre HL, Cullen JJ (1996) Primary production by suspended and benthic microalgae in a turbid estuary: time scales of variability in San Antonio Bay, Texas. Mar Ecol Prog Ser (in press)

MacIntyre HL, Geider RJ, McKay RM (1996) Photosynthesis and regulation of Rubisco activity in net phytoplankton from Delaware Bay. J Phycol 32:718-731

MacIntyre S (1993) Vertical mixing in a shallow eutrophic lake: possible consequences for the light climate of phytoplankton. Limnol Oceanogr 38:798-817

Mallin MA, Paerl HW (1992) Effects of variable irradiance on phytoplankton productivity in shallow water. Limnol Oceanogr 37:54-63

Marra J (1978a) Effect of short-term variations in light intensity on photosynthesis of a marine phytoplankter: a laboratory simulation study. Mar Biol 46:191-202

Marra J (1978b) Phytoplankton photosynthetic response to vertical movement in a mixed layer. Mar Biol 46 $203-208$
Marra J, Heinemann K (1982) Photosynthesis response by phytoplankton to sunlight variability. Limnol Oceanogr 27:1141-1153

Mouget JL, Legendre L, de la Noüe J (1993) Initial and tota] activity of Rubisco in Scenedesmus ecornis: is the French press a suitable tool for enzyme extraction? Plant Cell Physiol 34:281-288

Mukerji D, Morris I (1976) Photosynthetic carboxylating enzymes in Phaeodactylum tricornutum: assay methods and properties. Mar Biol 36:199-206

Neale PJ, Marra J (1985) Short-term variation of $P_{\max }$ under natural irradiance conditions: a model and its implications Mar Ecol Prog Ser 26:113-124

Neale PJ, Richerson PJ (1987) Photoinhibition and the diurnal variation of phytoplankton photosynthesis. I. Development of a photosynthesis-irradiance model from studies of in situ responses. J Plankton Res 9:167-193

Pahl-Wostle C, Imboden DM (1990) DYPHORA — a dynamic model for the rate of photosynthesis of algae. J Plankton Res 12:1207-1221

Pearcy RW (1990) Sunflecks and photosynthesis in plant canopies. Ann Rev Plant Physiol Plant Mol Biol 41. $421-453$

Pearcy RW (1995) Photosynthetic response to sunflecks and light gaps: mechanisms and constraints. In: Baker NR, Bowyer JR (eds) Photoinhibition of photosynthesis from molecular mechanisms to the field. Bios, Oxford, p $255-271$

Pejrup M (1986) Parameters affecting fine-grained suspended sediment concentrations in a shallow micro-tidal estuary Ho Bugt Denmark. Estuar Coast Shelf Sci 22:241-254

Pennock JR, Sharp JH (1986) Phytoplankton production in the Delaware estuary: temporal and spatial variability. Mar Ecol Prog Ser 34:143-155

Randall JM, Day JW (1987) Effects of river discharge and vertical circulation on aquatic primary production in a turbid Lounsiana (USA) estuary. Neth J Sea Res 21:231-242

Rivkin RB (1990) Photoadaptation in marine phytoplankton variations in ribulose 1,5-bisphosphate activity. Mar Ecol Prog Ser 62:61-72

Sassenrath-Cole GF, Pearcy RW (1992) The role of ribulose1,5-bisphosphate regeneration in the induction requirements of photosynthetic $\mathrm{CO}_{2}$ exchange under transient light conditions. Plant Physiol 99:227-234

Sassenrath-Cole GF, Pearcy RW, Steinmaus S (1994) The role of enzyme activation in limiting carbon assimilation under variable light conditions. Photosynth Res 41:295-302

Seemann JR, Kobza J, Moore Bd (1990) Metabolism of 2-carboxyarabinitol 1-phosphate and regulation of ribulose1,5-bisphosphate carboxylase activity. Photosynth Res 23 $119-130$

Sharkey TD (1990) Feedback limitation of photosynthesis and the physiological role of ribulose-bisphosphate carboxylase carbamylation. Bot Mag Tokyo Spec Iss 2:87-105

Sharkey TD, Stitt M, Heineke D, Gerhardt R, Raschke K, Heldt HW (1986) Limitation of photosynthesis by carbon metabolism. II. $\mathrm{O}_{2}$-insensitive $\mathrm{CO}_{2}$ uptake results from limitation of triose phosphate utilization. Plant Physiol 81 $1123-1129$

Vincent WF, Neale PJ, Richerson PJ (1984) Photoinhibition: algal responses to bright light during diel stratification and mixing in a tropical alpine lake. J Phycol 20:201-211

Webb WL, Newton M. Starr D (1974) Carbon dioxide exchange of Alnus rubra: a mathematical model. Oecologia 17:281-291

Whitney SM, Yellowlees D (1995) Preliminary investigations into the structure and activity of ribulose bisphosphate 
carboxylase form two photosynthetic dinoflagellates. J Phycol 31:138-146

Woodrow IE, Mott KA (1989) Rate limitation of non-steadystate photosynthesis by ribulose-1,5-bisphosphate carboxylase in spinach. Aust J Plant Physiol 16:487-500

Woodrow IE, Mott KA (1992) Biphasic activation of ribulose

This article was submitted to the editor bisphosphate carboxylase in spinach leaves as determined from nonsteady-state $\mathrm{CO}_{2}$ exchange. Plant Physiol 99 298-303

Yoder JA, Bishop SS (1985) Effects of mixing-induced irradiance fluctuations on photosynthesis of natural assemblages of coastal phytoplankton. Mar Biol 90:87-93

Manuscript first received: October 17, 1995

Revised version accepted: September 24, 1996 